\title{
Designing High-Freedom Responsive Feeder Transit System with Multitype Vehicles
}

\author{
Zhengwu Wang, ${ }^{1,2}$ Jie Yu $\mathbb{D}^{1,2}$ Wei Hao ${ }^{1 D},{ }^{1,2}$ Tao Chen, ${ }^{1}$ and Yi Wang ${ }^{3}$ \\ ${ }^{1}$ Hunan Key Laboratory of Smart Roadway and Cooperative Vehicle-Infrastructure Systems, \\ Changsha University of Science and Technology, Changsha 410114, China \\ ${ }^{2}$ School of Traffic and Transportation Engineering, Changsha University of Science and Technology, Changsha 410114, China \\ ${ }^{3}$ International Business School, Hunan University of Technology and Business, Changsha 410205, China \\ Correspondence should be addressed to Jie Yu; jiaotongyujie@163.com and Wei Hao; haowei@csust.edu.cn
}

Received 3 January 2020; Revised 31 May 2020; Accepted 8 July 2020; Published 25 July 2020

Academic Editor: Yu Jiang

Copyright (c) 2020 Zhengwu Wang et al. This is an open access article distributed under the Creative Commons Attribution License, which permits unrestricted use, distribution, and reproduction in any medium, provided the original work is properly cited.

\begin{abstract}
The last mile travelling problem is the most challenging part when using public transit. This study designs a high-freedom responsive feeder transit (HFRFT) system to serve at the transfer station, given vehicle routes, departure time, and service area based on demand. The proposed feeder transit system employs a travelling mode with multitype vehicles. In order to improve the operation of the HFRFT system, the optimization design methods are suggested for vehicle routes, scheduling, and service area. A mixed integer programming model and its hybrid of a metaheuristic algorithm are proposed to efficiently and integrally solve the vehicle routes and scheduling parameters according to the reservation requirements. A heuristic method is proposed to optimize the service area based on the equilibrium of system supply and demand. Case studies show that the mixed running mode of multiple models can significantly improve the seat utilization, which can also significantly reduce the number of departures and the average travel distance per passenger. The proposed service area optimization method is proved to be feasible to improve the last mile travel.
\end{abstract}

\section{Introduction}

In areas where passenger travel density is low, fixed route transit (FRT) has a low seat utilization rate due to low and scattered passenger flow. The bus company has a low operating efficiency, which is difficult to sustain. With the development of communication technology and automatic control technology, intelligent public transportation has gradually become a major trend in the development of traffic field [1-7]. Consequently, the public transportation field is largely affected by the Internet Plus Era, and passenger information can connect with bus company in real time. Using the Internet-of-things, passengers can indicate their own travel needs through online travel information platforms, and bus companies can also plan bus schedules based on passenger travel information and actual operating conditions in response to the travel demand. In recent years, a new kind of transportation mode called demand-responsive transit (DRT) has emerged. Compared with the conventional FRT, DRT can realize door-to-door service and effectively solve the last mile travelling problem with improved mobility and flexibility. Moreover, DRT is more suitable for low-density residents' travel areas and disadvantaged people (the elderly, the disabled, etc.) than FRT.

Responsive feeder transit (RFT) is a special form of demand-responsive transit (DRT), also known as demandresponsive connector (DRC), which is a flexible transit service because it operates in a demand responsive fashion within a service area and moves customers to/from a transfer point that connects to an RFT network [8]. RFT services have a significant advantage that they can increase the service coverage and accessibility compared with traditional fixed route transit, by offering a capacity with better alignment $[9,10]$. 
Most of the current studies on DRT (shown in Table 1) focused on the vehicle's routing model, coordinated application of DRT and FRT, key parameters such as service performance, scheduling parameters including vehicle departure time, total number of vehicles, vehicle type etc., geometric features in the service area, critical demand density, and so on. However, limited studies have been conducted to study the coordination of vehicle routes and schedules.

In many cases of DRT, vehicle running mode can involve four types, as shown in Figure 1. Type A is the main running mode of mobility allowance shuttle transit (MAST) [51], high-coverage point-to-point transit [57], and demand-responsive feeder transit circulator [13]. Type B is the main running mode of dial-a-ride $[18,19]$. Type $\mathrm{C}$ and $\mathrm{D}$ are both the main running modes of RFT $[15,30]$.

In Figure 1, the running route and bus stop of type A are basically fixed with only part of the route being adjusted according to the passengers' demands, and passengers are allowed to get on and off at the middle stops and the terminal stops. Meanwhile, the running route and service areas of type $\mathrm{B}$ are not fixed. After the vehicle completing one journey, it will continue the next journey; both type $\mathrm{C}$ and type $\mathrm{D}$ operate around the transfer station (the service area is relatively fixed), and the terminal stops are located at the transfer stations. Type $\mathrm{C}$ can only pick up passengers from the middle stops to the transfer station or from the transfer station to the middle stops, while type D can pick up passengers from the middle stops to the transfer station and from the transfer station to the middle stops simultaneously.

RFT can be divided into two categories based on the freedom of service areas, running route, and bus stops.

1.1. Low-Freedom RFT. Low-freedom RFT (LFRFT), whose terminal stops and some sections of the route and middle stops are fixed when others may be limitedly adjusted, can only respond to passengers' demands to a lower degree. LFRFT is formed by partially adjusting FRT (Nourbakhsh and Ouyang [28], Yu et al. [13], Guo et al. [10], Lu et al. [40, 41], Gschwender et al. [36], Alshalalfah and Shalaby [29], and so on) (shown in Table 2).

1.2. High-Freedom RFT. For the high-freedom RFT (HFRFT), the service area and terminal stops are fixed. HFRFT can respond to passengers' demands to a greater extent. In HFRFT, running route, vehicle departure time, middle stops, stay times, and so on are optimally determined according to passenger demand. HFRFT has attracted the attention of some researchers, such as $\mathrm{Li}$ and Quadrifoglio [8], Edwards and Watkins [32], Sun et al. [20], and so on (shown in Table 2).

Table 2 summarizes previous studies on RFT. One of the remarkable features of RFT is that the analytical model and planning model have been proposed to optimize the RFT service under the reservation demands. For example, Chandra and Quadrifoglio [30], Edwards and Watkins [32], and Nourbakhsh and Ouyang [28] came up with a structured flexible transit system and built the optimization model to seek the optimum network layout, service area of each bus, and bus headway. Pan et al. [15] proposed a mixed integer linear programming model to optimize the service area and transit route planning concurrently, which features a two-level structure with an upper level to maximize the number of served passengers by the feeder transit system and a lower level to minimize the operational cost for transit operators. However, several gaps still remain in previous studies:

(i) Research on optimizing path and scheduling simultaneously is quite limited, although some studies have determined departure time according to the routes required to reservation demands $[15,20,36]$.

(ii) Optimization of service areas is rarely involved when the optimization design is carried out under fixed regular service area. In fact, the service area and road network are random because land use and travel demand are not evenly distributed. Optimization of service area can fully improve the system efficiency while system demands are met. At the same time, it can also facilitate to fulfill transfer services by subareas and avoid the crossover of service areas.

(iii) Some assumptions are inconsistent with reality, such as the uniform distribution of passengers, regular service area, only one type of vehicle, and unlimited vehicle capacity. In fact, vehicle capacity has a strong effect to vehicle route and scheduling. Moreover, the impact in the mixed running mode including both pick-up and deliver passengers is even greater because deliveries at each demand point will affect pickups in subsequent and pre-sequent stations, e.g., Kirchler and Wolfler Calvo [19]. As the demand for passengers increases in the service area, it may be necessary to choose larger capacity vehicles and operate multiple vehicles at the same time (Ceder [59], Guedes and Borenstein [60]).

In light of the above deficiencies, taking the mixed running mode with capacity constraint as the research object, this study proposes a integration optimization method for multitype vehicle routes and schedule on the basis of reservation requirements. The remainder of the paper is organized as follows. Section 2 presents a mixed integer programming (MIP) model and its solution algorithm for multitype vehicle routes and schedule problem. Section 3 puts forward a heuristic method to optimize service area according to the principle of capacity and demand equilibrium. Section 4 displays a case to illustrate the proposed model and algorithm. Some concluding remarks and possible future work are given in Section 5.

\section{MIP Model and Its Solution Algorithm for Route and Scheduling}

2.1. Problem Statement. The application scenarios of HFRFT under the mixed running mode, capacity constraint, 
TABLE 1: A summary of existing studies on DRT.

\begin{tabular}{ll}
\hline Research content & Papers
\end{tabular}

Vehicle routing model

Saberi and Verbas [11]; Yan et al. [12]; Yao et al. [13]; Ma et al. [2, 3]; Dessouky et al. [14]; Pan et al. [15]; Núñez et al. [16]; Ghannadpour et al. [17]; Schilde et al. [18]; Kirchler and Calvo [19]; Sun et al. [20]; Yu et al. [13]; Tang et al. [21]

Coordinated application of DRT and FRT

Aldaihani et al. [22]; Sheu [23]; Guo et al. [10]; Rahimia et al. [24]; Chen and Nie [25]; Qiu et al [26]

Service performance

Alshalalfah and Shalaby [27]; Nourbakhsh and Ouyang [28]; Alshalalfah and Shalaby [29]; Chandra and Quadrifoglio [30, 31]; Edwards and Watkins [32]; Kelly et al. [33]; Engelen et al. [34]; Freia et al [35]; Gschwender et al. [36]; Rahimia et al. [24];

Scheduling parameters Kikuchiand Donnelly [37]; Hsu [38]; Nair and Miller-Hooks [39]; Lu et al. [40, 41]; Zheng et al. [42]; Rahimi et al. [24]; Tang et al. [43]; Guo et al. [44]; Chandra and Quadrifoglio [45]; Dessouky and Adam [46]; Nourbakhsh and Ouyang [28]; Gschwender et al. [36]

Geometric features in the service Zhao and Dessouky [47]; Li and Quadrifoglio [48]; Errico et al. [49]; Chandra and Quadrifoglio area [30, 31]; Li and Quadrifoglio [50];

Critical demand density $\quad$ Quadrifoglio et al. [51-53]; Amiripour et al. [54]; Frei et al. [35]

Site selection $\quad$ Pratelli and Schoen [55]; Razi and Muhammad [56]

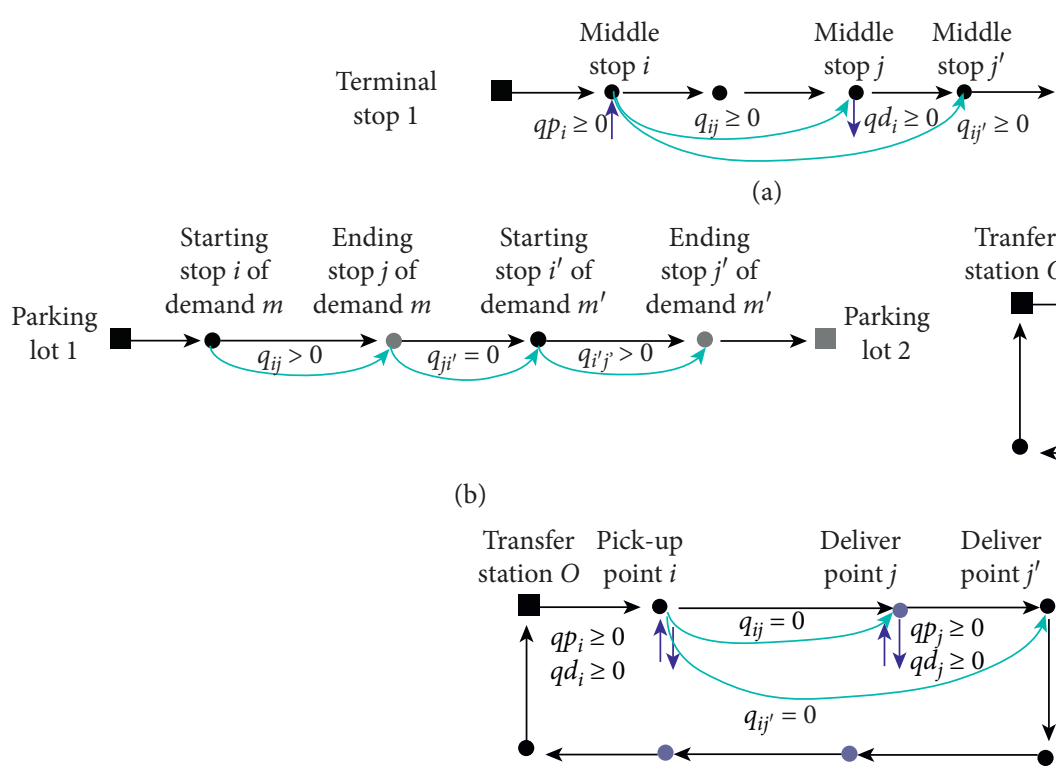

(d)

Figure 1: Four types of vehicle running modes $\left(q_{i j}(i\right.$ or $j \neq o)$ are the demands from stop $i$ to stop $j$, and $q p_{i}$ and $q d_{i}$ are the number of pick-up or deliver passengers in the stop $i$, respectively). (a) Type A. (b) Type B. (c) Type C. (d) Type D.

multi-type vehicle, and reservation requirements are listed as follows.

There are a certain number of multitype vehicles. For the actual bus operation, there are usually two passengers' types in the system, one is passengers from different places to the transfer station and the other is passengers from the transfer station to different places, both of which are limited by the time window. We define these two types of passengers as those who need to be picked up and need to be sent, respectively. According to the different types of passengers, the bus running mode can be divided into alone running mode (only pick-up or deliver) and mixed running mode (both pick-up and deliver), as shown in Figure 2. The same shift of the former is only allowed to serve the passengers need to be picked up or sent, while the latter is allowed to serve the passengers need to be picked up and sent at the same time. These passengers can send their own travelling information to the transit companies via customer service, mobile phone, or Internet, and the travelling information includes travel demand, boarding time/get-off time, pick-up location/deliver location, etc. After collecting the travelling information, the transit company arranges a team of vehicles to complete all passengers' transfer tasks and maximize the system's total benefit through the adjustment of departure time, vehicle type, and running route of all vehicles under passenger time window and vehicle capacity constraints.

Firstly, aiming at the maximum total benefit of the HFRFT system, the coordinated optimization model of vehicle routing and scheduling is constructed under the constraints of vehicle capacity, passenger time window, and 


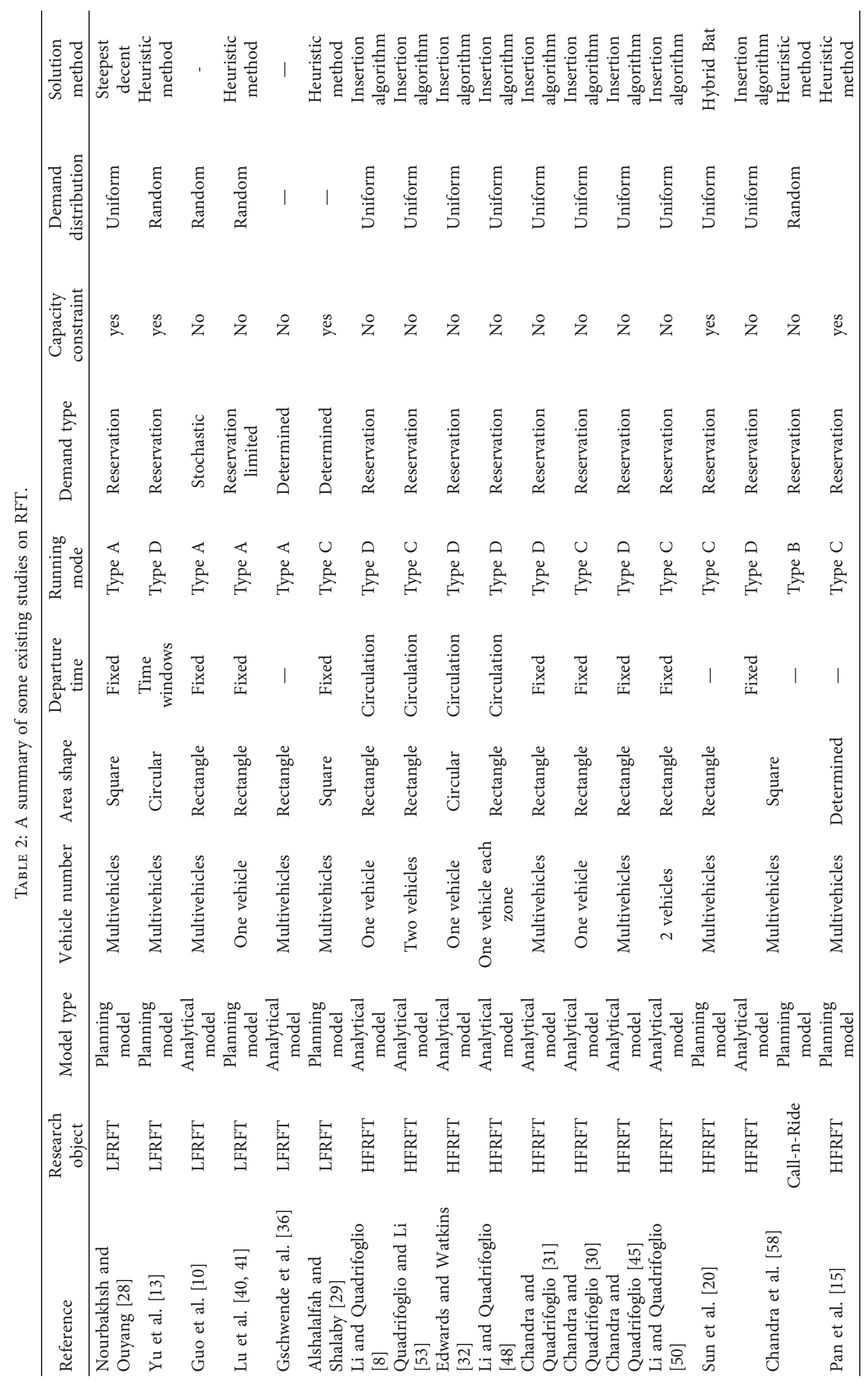




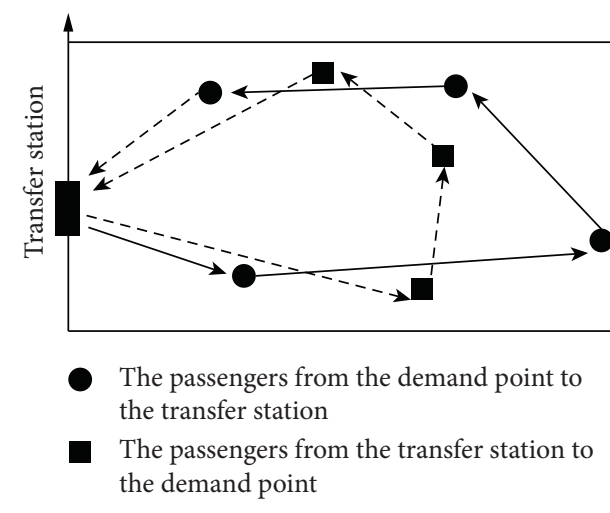

(a)

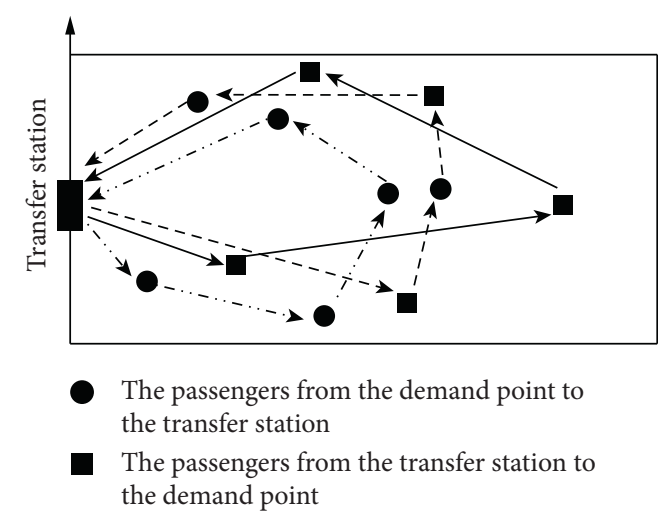

(b)

FIgUre 2: The vehicle route of different operation modes. (a) Alone running mode (only pick-up or deliver). (b) Mixed running mode (both pick-up and deliver).

maximum one way running time of vehicle. In the process of model construction, considering the problems of high repetition rate of running path and low average seat utilization rate of vehicles in the alone running mode, the mixed running mode with simultaneous pick up and deliver is proposed. In order to compare the performance of different running modes, it is assumed that there are three types of vehicles in RFT system, i.e., vehicles can only pick up, vehicles can only deliver, and vehicles can pick up and deliver simultaneously. Secondly, combined with the above coordination optimization model, the optimization method of service area is proposed based on the matching of transportation capacity and passenger demand.

2.2. Assumptions. The following assumptions are made to ensure that the proposed formulations are tractable and realistically reflect the real-world constraints:

(i) The feeder bus begins and ends each of its trips at the transfer station.

(ii) Pick-up/deliver requests sent by the passengers are collected and responded to before the beginning of each trip.

(iii) Running speed of all type vehicles is the same on all road sections.

(iv) There are enough vehicles to meet all passenger requests. All requests are responded in service area and passengers do not cancel requests.

(v) The pick-up passenger has only time window constraint on the boarding point and the deliver passenger has the drop-off point.

2.3. Notations. To facilitate model presentation, key parameter definitions and notations used subsequently are summarized in the notation list (Table 3).

2.4. Model Formulation. Given the above assumptions and definitions, the problem of deciding vehicle routes and scheduling for a HFRFT system can be formulated with the following MIP model which is similar to Wang et al. [61]. In the MIP model, the vehicle route determined by pick-up or deliver passengers is proposed (shown in Figure 3). This new route representation method can fully reflect the personality of the passenger time window and express accurately the route nonrepeated sections because each passenger can only pick up/deliver once. However, if the vehicle route is usually determined by demand points passed, there may be many demand points repeatedly on the routes and the routes are not easily distinguished.

In the MIP model, the optimization objective is to maximize system total benefit $E$, expressed as equation (1), which is the difference between operating income and operating costs. The former is fare income, $E_{1}$, of all passengers, expressed as equation (2), when the latter is made up of $E_{2}$, $E_{3}$, and $E_{4}$, expressed as equations (3)-(5), respectively:

$$
\begin{aligned}
E & =w_{1} E_{1}-\left(w_{2} E_{2}+w_{3} E_{3}+w_{4} E_{4}\right), \\
E_{1} & =\sum_{v} \sum_{k}\left|\mathbf{N}_{v k}\right| \cdot C, \\
E_{2} & =\sum_{v} \sum_{k}\left[C_{v} \cdot x_{v k}+\sum_{m} \sum_{n} L_{m n} \cdot x_{v k m n} \cdot G_{v}\right], \\
E_{3} & =\sum_{v} \sum_{k}\left[P E_{m} \cdot\left(D_{v k}+\sum_{m} x_{v k m} \cdot \theta_{v k m}\right)\right], \\
E_{4} & =\sum_{v} \sum_{k} \sum_{m} x_{v k m} \cdot P L_{m},
\end{aligned}
$$

where the RHS in equation (2) is fare income for all passengers when a one-ticket transit system is used. The RHS of equation (3) is vehicle operating cost made up of fixed use cost and travel cost of all shifts. The terms in the right hand side of equations (4) and (5) are the penalty cost of all shifts for early arrival and late arrival, respectively.

The proposed model is expressed as a MIP problem, as shown in the following equations: 
TABle 3: The notation list.

\begin{tabular}{|c|c|}
\hline $\mathrm{O}$ & Transfer station \\
\hline $\mathbf{N}=\{1,2, \ldots, a\}$ & The set of passengers scheduled to go to the transfer point \\
\hline $\mathbf{B}=\{a+1, a+2, \ldots, a+b\}$ & The set of passengers scheduled to leave the transfer point \\
\hline $\begin{array}{l}\mathrm{NB}=\{1,2, \ldots, \mathrm{a}, a+1 \\
a+b\}\end{array}$ & The set of all passengers \\
\hline$m, n \in \mathbf{N B}$ & The $m$ th and $n$th passengers \\
\hline$V$ & The type of feeder vehicle \\
\hline$M, M v$ & The set of feeder vehicles and the type $v$ vehicle, respectively \\
\hline$k \in\{1,2, \ldots, K\}$ & The $k$ th shift, and each shift corresponds only to one vehicle type \\
\hline K & The maximum shift \\
\hline$t_{v k m}$ & The time when the $k$ th shift (belongs to type $v$ vehicle) arrives at demand point of passenger $m$ \\
\hline$U T_{m}, L T_{m}$ & $\begin{array}{c}\text { Time window upper and lower bounds on the boarding point for pick-up passenger } m \text { or on the drop-off } \\
\text { point for deliver passenger } m\end{array}$ \\
\hline$C_{v}, G_{v}$ & Fixed use cost per shift (\$/shift) and travel cost unit mileage $(\$ /$ mile) of type $v$, respectively \\
\hline$Q_{v}$ & The capacity of type $v$ (people) \\
\hline C & Ticket price (\$/people) \\
\hline $\mathbf{N}_{v k}$ & Passengers' set of the $k$ th shift (belongs to type $v$ vehicle) \\
\hline$L_{m n}, t_{m n}$ & $\begin{array}{c}\text { Shortest path distance (miles) and time (hours) from demand point of passenger } m \text { to passenger } n \text {, } \\
\text { respectively }\end{array}$ \\
\hline$V$ & Vehicle speed (miles/hour) \\
\hline$D_{v k}$ & $\begin{array}{c}\text { The number of passengers in the feeder vehicle when the } k \text { th shift (belongs to type } v \text { vehicle) driving away } \\
\text { from the transfer station }\end{array}$ \\
\hline$T$ & The maximum running time in one-way (hours) \\
\hline$T_{v k}$ & The departure time of the $k$ th shift (belongs to type $v$ vehicle) \\
\hline$D T_{m}$ & The reservation departure time from the transfer station of passenger $m$ \\
\hline$x_{v k m n}$ & $\begin{array}{c}\text { Binary variable } x_{v k m n}=1 \text { if the } k \text { th shift (belongs to type } v \text { vehicle) is driving from demand point of passenger } \\
\qquad m \text { to passenger } n \text {, otherwise } 0\end{array}$ \\
\hline$x_{v k}$ & Binary variable $x_{v k m n}=1$ if the $k$ th shift (belongs to type $v$ vehicle) is used, otherwise 0 \\
\hline$x_{v k m}$ & $\begin{array}{c}\text { Binary variable } x_{v k m}=1 \text { if the } k \text { th shift (belongs to type } v \text { vehicle) is passing the demand point of passenger } m \text {, } \\
\text { otherwise } 0\end{array}$ \\
\hline$\theta_{v k m}$ & $\begin{array}{c}\text { Binary variable. } \theta_{v k m}=1 \text { if passenger } m \text { is taking the } k \text { th shift (belongs to type } v \text { vehicle) to the transfer } \\
\text { station, otherwise }-1\end{array}$ \\
\hline$x_{v k m n}$ & $\begin{array}{c}\text { Binary variable. } x_{v k m n}=1 \text { if the } k \text { th shift (belongs to type } v \text { vehicle) is driving from demand point of passenger } \\
m \text { to passenger } n \text {, otherwise } 0\end{array}$ \\
\hline$P E_{m}, P L_{m}$ & Penalty function for early and late arrival at the demand point of passenger $m$, respectively \\
\hline$P E_{v k m}$ & Early arrival time of the $k$ th shift (belongs to type $v$ vehicle) at the demand point of passenger $m$ \\
\hline$E_{1}$ & Fare income of all passenger $(\$)$ \\
\hline$E_{2}$ & Vehicle operating cost of all shifts $(\$)$ \\
\hline$E_{3}, E_{4}$, & Penalty cost of all vehicles for early arrival and late arrival, respectively $(\$)$ \\
\hline$\alpha, \beta$ & Penalty parameters for early and late arrival, respectively \\
\hline$w_{1}, w_{2}, w_{3}, w_{4}$ & Weight coefficients, respectively \\
\hline$\rho, \zeta, \varsigma$ & Connection degree, number of sections, number of nodes for road network \\
\hline MP & Mutation probability in GA \\
\hline $\mathrm{cr}, W_{0}, W_{\text {end }}$, and $\mathrm{CL}$ & Cooling rate, initial temperature, end temperature, chain length in SA, respectively \\
\hline $\mathrm{Z}$ & Iteration step in service area optimization \\
\hline$Z \zeta$ & Service area of one block expanded in step $\zeta$ \\
\hline$S_{\zeta}$ & Service area in step $\zeta$ \\
\hline $\mathrm{Sd}_{\zeta}$ & Expansion direction in step $\zeta$ \\
\hline $\mathbf{S D}_{\zeta}$ & Expansion direction set in step $\zeta$ \\
\hline
\end{tabular}

$\operatorname{Max} \mathrm{E}$

$$
\begin{aligned}
\text { s.t. } D_{v k}+ & \sum_{m} x_{v k m} \cdot \theta_{v k m} \leq Q_{v}, \quad \forall m \in \mathbf{N B}, \\
& \mathbf{N}_{v k} \cap \mathbf{N}_{v_{l} k_{\prime}}=\varnothing, \quad \forall k \neq k^{\prime} \text { and } \forall v \neq v^{\prime},
\end{aligned}
$$

$$
P E_{m}= \begin{cases}0, & \text { if } T_{m} \leq t_{v k m} \leq U T_{m} \\ \alpha\left(L T_{m}-t_{v k m}\right), & \text { if } t_{v k m} \leq L T_{m} \text { and } \theta_{v k m}=1, m \in \mathbf{N}_{v k}, \\ 0, & \text { if } t_{v k m} \leq L T_{m} \text { and } \theta_{v k m}=-1,\end{cases}
$$

$$
\begin{aligned}
& P L_{m}=\left\{\begin{array}{ll}
0, & \text { if } L T_{m} \leq t_{v k m} \leq U T_{m}, \\
\beta\left(t_{v k m}-U T_{m}\right), & \text { if } t_{v k m}>U T_{m},
\end{array} \quad m \varepsilon \mathbf{N}_{v k},\right. \\
& P E_{v k m}= \begin{cases}L T_{m}-t_{v k m}, & \text { if } \theta_{v k m}=1, \\
0, & \text { if } \theta_{v k m}=-1,\end{cases} \\
& \sum_{m} \sum_{n} t_{m n} \cdot x_{v k m n}+\sum_{m} \max \left(P E_{v k m}, 0\right) \leq T, \quad m, n \in \mathbf{N}_{v k},
\end{aligned}
$$



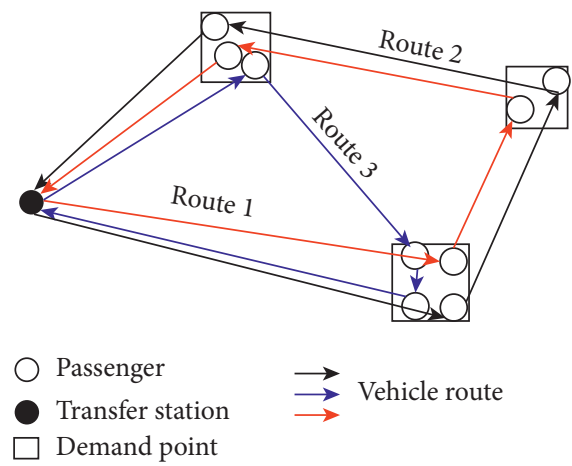

FIGURE 3: Vehicle route represented by passengers.

$$
\begin{gathered}
\sum_{n} x_{v k O n}=\sum_{m} x_{v k m O}=1, \quad m, n \in \mathbf{N B}, \\
D T_{m}<T_{v k}, \quad \forall m \in \mathbf{N}_{v k}, \\
\sum_{v} \sum_{k} x_{v k m}=1, \quad \forall m \in \mathbf{N B} .
\end{gathered}
$$

In the model, equation (7) considers the vehicle capacity. Equation (8) determines each passenger can only be served by one vehicle. Equation (9) is the early arrival penalty cost only for pick-up passengers while the early arrival penalty cost is zero for deliver passengers because of vehicle waiting at the transfer station. Equations (10) and (11) are the late arrival penalty cost and the early arrival time, respectively. Equation (12) is the maximum run-time constraint. Equation (13) ensures vehicle depart from and return to the transfer station. Equation (14) ensures departure time is earlier than the reservation time for deliver passengers leaving the transfer station. Equation (15) ensures all reservation passengers will be served.

2.5. Solution Algorithm. The MIP model, constructed by equations (6)-(15), represents a more complicated vehicle routing problem (VRP) that is solved by heuristic algorithm, such as genetic algorithm (GA) [62-64], hyperheuristic algorithm [65], and hybrid of metaheuristic algorithm [66]. Ho et al. [67] argues that combining metaheuristics with other types of metaheuristics and mathematical programming is a growing trend to solve the DAR problem, and hybrids of metaheuristics usually come into two forms: (i) each metaheuristic is executed sequentially and (ii) a metaheuristic is executed within another metaheuristic. We adopt the second form, where GA is executed within simulated annealing (SA) to solve MIP model's abovementioned problem (as shown in Figure 4).

In Figure 4, firstly, based on GA, vehicle types and routes are optimized when departure intervals are known. Then, departure intervals are adjusted using the SA algorithm. GA is used again to optimize vehicle types and routes. This process is repeated until the ideal solution is obtained.

In the hybrid of metaheuristic, multichromosome encoding is used where both passengers and vehicles are encoded based on natural numbers, respectively. In initialization, $r$ chromosomes are generated. Moreover, each chromosome contains a vehicle gene and a passenger gene. The code length of the former and the latter is $a+b$, and $K$, in this paper, is the number of reservation passengers and departure vehicles, respectively. When generating the initial populations, considering that the solution quality and efficiency of the heuristic algorithm depend on the quality of the initial solution, the generation of feasible solution itself is a NP-hard problem. Based on the initialization method proposed by Solomon [68], the improved nearest neighbor algorithm based on minimum cost (NNC algorithm) was designed to generate initial feasible populations. The algorithm flow is as follows:

Step 1: randomly set the departure time; the feeder bus starts from the transfer station (select the largest capacity vehicle)

Step 2: select an unserved passenger closest to the last served passenger; if the constraint conditions are satisfied, insert the passenger into the current running route

Step 3: repeat Step 2; if the capacity limit or maximum travel time limit of the current vehicle has been reached, go to Step 1 until all passengers have been served.

The "distance" (i.e., insertion cost) $f_{m n}$ between two passengers in the algorithm flow is defined as follows:

$$
f_{m n}=\alpha_{1} t_{m n}^{v k}+\alpha_{2} E_{m n}^{v k}+\alpha_{3} L_{m n}^{v k}+\alpha_{4} W_{m n}^{v k} \text {, }
$$

where $t_{m n}^{v k}$ denotes travel time of $k$ th shift (belongs to type $v$ vehicle); $E_{m n}^{v k}$ is the difference between arrival time and start time, $E_{m n}^{v k}=\left|L T_{n}-t_{v k n}\right| ; L_{m n}^{v k}$ is the difference between the arrival time and the end time; $L_{m n}^{v k}=\left|U T_{n}-t_{v k n}\right| ; W_{m n}^{v k}$ is the sum of the travel time and the minimum possible waiting time; $W_{m n}^{v k}=t_{m n}^{v k}+\max \left\{0,\left(L T_{n}-t_{v k n}\right)\right\} ; \alpha_{i}$ denotes random parameter; and $\sum \alpha_{i}=1$.

In $\mathrm{GA}$, the fitness is the system total benefit; the selection method is roulette; the selection probability is proportional fitness; inner and interindividual crossovers are both adopted, respectively, for vehicle gene and passenger gene; the mutation probability is set to MP.

In $\mathrm{SA}$, some parameters, such as cooling rate $c r$, initial temperature $W_{0}$, end temperature $W_{\text {end }}$, and chain length CL ( $=K$ in this paper), are determined; the code method is also a natural number; the new solution is based on the random disturbance and feasibility analysis; the Metropolis guideline is applied to determine whether the new solution is accepted.

\section{Optimization Method of Service Area}

The influence factors of the HFRFT service area include road network characteristics, passenger's demand distribution, and feeder facility performances. These factors together affect the shape and size.

Road network form is the important influence factor of service area. So far, the shape of service area is divided into 


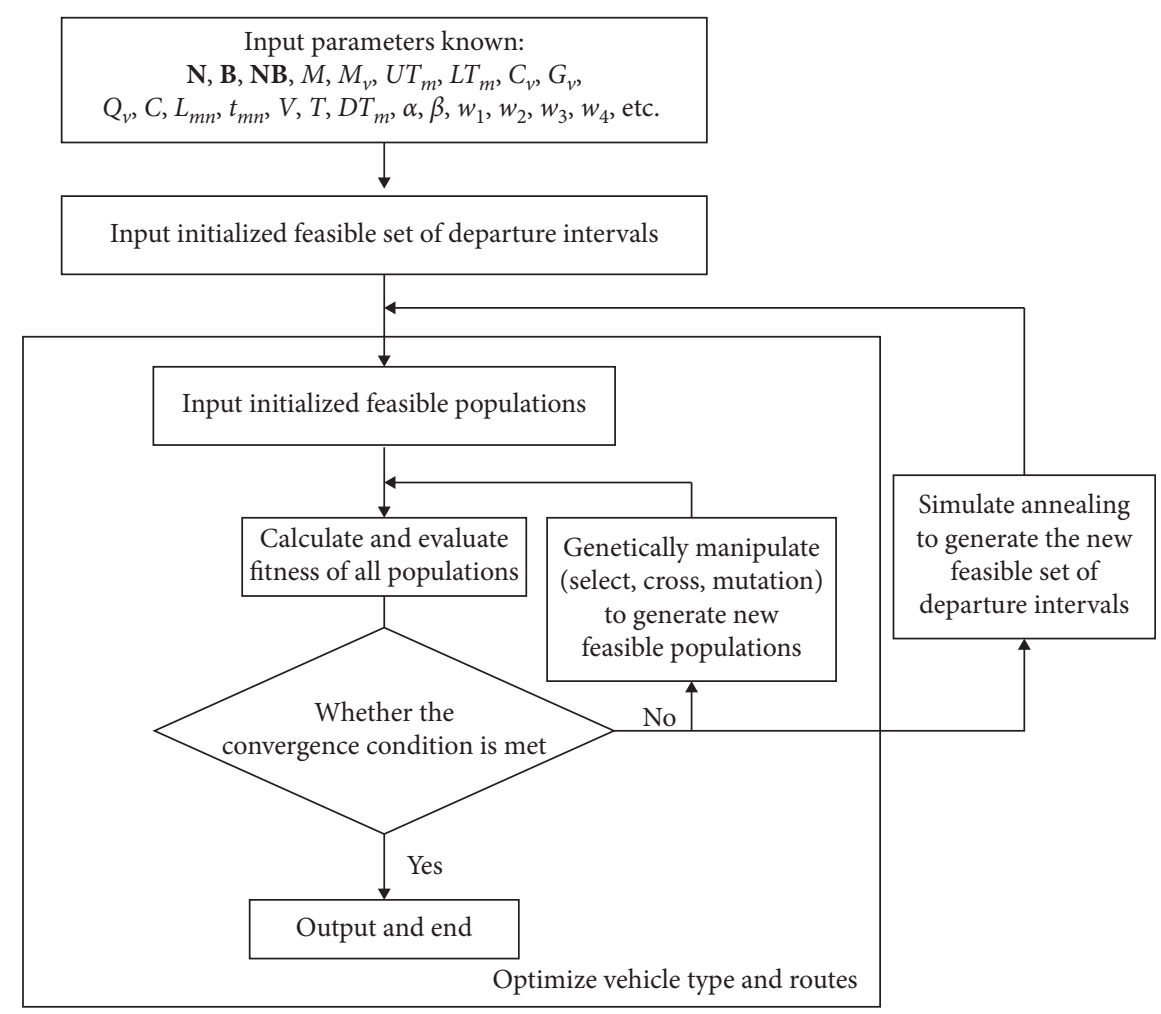

FIgURE 4: Flow chart of the hybrid of metaheuristic.

ideal regularity shape where road network form is assumed to be regular $[8,50]$ and actual irregularity shape $[14,15]$. Moreover, the square road network form is suitable for the rectangular service areas while the radial network shape road network is suitable for the circular service areas. Other characteristics of the road network such as density and connectivity affect the size of service area to a certain extent. The bigger the road network density, the closer the feeder transit can be to the residential point. The higher the road network connectivity, the larger area the feeder system can serve because demand point can be reached more easily.

The temporal and spatial distribution characteristics of passenger demands are also the important factors. If other conditions are the same, the feeder transit in the low valley period can serve a larger area than the peak period; the feeder transit in low-density passenger area can serve larger scope than in the high-density passenger area.

The mode of route setting, the number and type of vehicles, and the running cycle of feeder facility performance are all important factors. The mode, in which the reference route exists, such as MAST, is generally used in the regular shape service area [51]. However, in HFRFT, whose vehicles have highly running freedom, the shape and size of the service area can be irregular and can be adjusted according to passenger demands. The more the pick-up and deliver capacity, determined by the number of vehicles and vehicle capacity, the larger the service area. At the same time, the longer the running cycle, the farther the feeder vehicle can travel, and the greater the service area can be.
The balance principle of capacity and demand is used to optimize service area. When road network and the number and type of vehicles are known, pick-up and deliver capacity can be obtained based on the MIP model. If demand distribution is also known in advance, the largest service area can be determined according to the balance principle. The optimization process is shown in Figure 5.

When determining the initial smaller service area $S_{0}, S_{0}$ should be included by the potential service area of HFRFT, determined by the reasonable attraction radius [69]. $S_{0}$ should be closed and be much smaller than the potential service area. If the MIP model is not solvable, the current system capacity cannot meet the system demand, that is, the system supply and system demand cannot be balanced.

In Figure 5, the expansion direction of service area is selected as follows:

(i) The expansion direction should have reservation requirements

(ii) After expanding a block, the service area will still be a closed area surrounded by roads

(iii) When there are multiple directions that can be expanded, the direction of the most demand points increased is preferentially chosen (other choice criteria such as the most passengers increased can also be used)

(iv) If there are multiple directions where demand points increased are the same, the direction of the largest connection degree $\rho$ for road network after expansion is preferentially chosen, where 


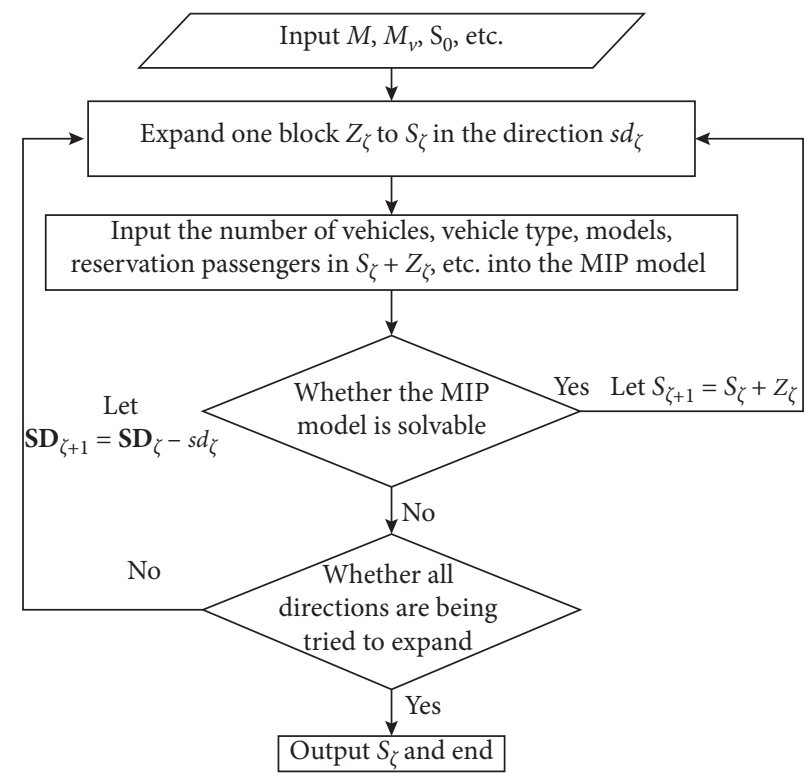

FIgURE 5: The optimization process of service area.

$$
\rho=\frac{2 \zeta}{\varsigma}
$$

\section{Case Study}

Shang Shuangtang Station of Changsha Metro Line 1 in Changsha City is selected as the sample. The models developed in this paper are used to obtain the optimal HFRFT system with an irregular area and road network. In the case study, the MIP model to coordinately optimize routes and scheduling is applied for the HFRFT system with the mixed running mode, and the optimization results are compared with the alone pick-up and alone deliver mode.

4.1. Basic Conditions. The scheduling cycle is $7: 00-8: 00$ a.m.; the radius of the circular area is 2.5 miles; the uniform speed $V$ is $21.7 \mathrm{miles} / \mathrm{h}$; the coordinate of the transfer station $O$ is $(0,0)$; there are two types of vehicles, $\mathbf{M}_{1}=\left\{M_{11}, M_{12}, M_{13}, M_{14}, M_{15}\right\}, \quad \mathbf{M}_{2}=\left\{M_{21}, M_{22}, M_{23}\right\}$, $Q_{1}=10$ people, $Q_{2}=15$ people, $C_{1}=9.3 \$ / \mathrm{shift}, Q_{2}=15.5$ $\$ /$ shift, $G_{1}=1.9 \$ /$ mile, $G_{2}=2.4 \$ / \mathrm{mile} ; T$ is $45 \mathrm{~min} ; C$ is 2.5 $\$$ /people; $w_{1}, w_{2}, w_{3}$, and $w_{4}$ are $1.0,1.0,2 / 3$, and $2 / 3$ respectively; $\alpha, \beta$ are $9.3 \$ / \mathrm{h}$ and $13 \$ / \mathrm{h}$, respectively; there are 1 transfer station and 25 demand points (shown in Figure 6 and Table 4) and 124 pick-up passengers to transfer station and 36 deliver passengers leaving the transfer station, whose time windows and locations are shown in Table 5. The distances between demand points are shown in Table 6 .

4.2. Route and Scheduling Optimization in Initial Service Area. According to the land use, the light green dotted area, surrounded by Wanjiali Rd.(S.), Furong Rd.(S.), Huanbao Rd.(W.), and Huijin Rd., is set as the initial service area (shown in Figure 6). In the initial service area, there are 59 reservation passengers. The computer program of the Figure 5 based on Matlab is operated to optimize routes and scheduling, and the results are shown in Tables 7-9.

If the number of the vehicles is sufficient and other parameters in the initial service area are still used, routes and scheduling optimization under pick-up and deliver alone is performed based on the MIP model changed slightly constraints for the mixed running. The results are shown in Tables 8 and 9 .

From Tables 7-9, comparing to the pick-up and deliver mode alone, the advantage of the mixed mode is obvious: the number of departures and vehicles required are reduced by $16.7 \%$ and $20 \%$, respectively. Also, average seat utilization rate is increased by $8.3 \%$. System total benefit $E$ becomes positive.

\subsection{Route and Scheduling Optimization in Optimal Service} Area. In Table 7, only 4 vehicles are needed, so the service area can be expanded. There are three expandable directions (shown in Figure 7). The number of new demand points is the same when expanding a block in three directions, so road network connectivity in three directions should be compared. Road network connectivity that expanded to the north, to the east, to the south is $2.72,2.61$, and 2.66 , respectively. Priority should be given to expanding the service area to the north. Loop this way until the optimal service area is obtained (dark green dotted line as shown in Figure 7).

In the service area surrounded by the dark green dotted line, all vehicles are used (according to the calculations followed); the number of departures is 9 , and the number of passengers served is 105. Based on Figure 5, the service area under irregular road network and scope can be optimized.

There are 105 reservation passengers in the optimal service area. The computer program of Figure 4 is again utilized, and the results are shown in Tables 10-12. 


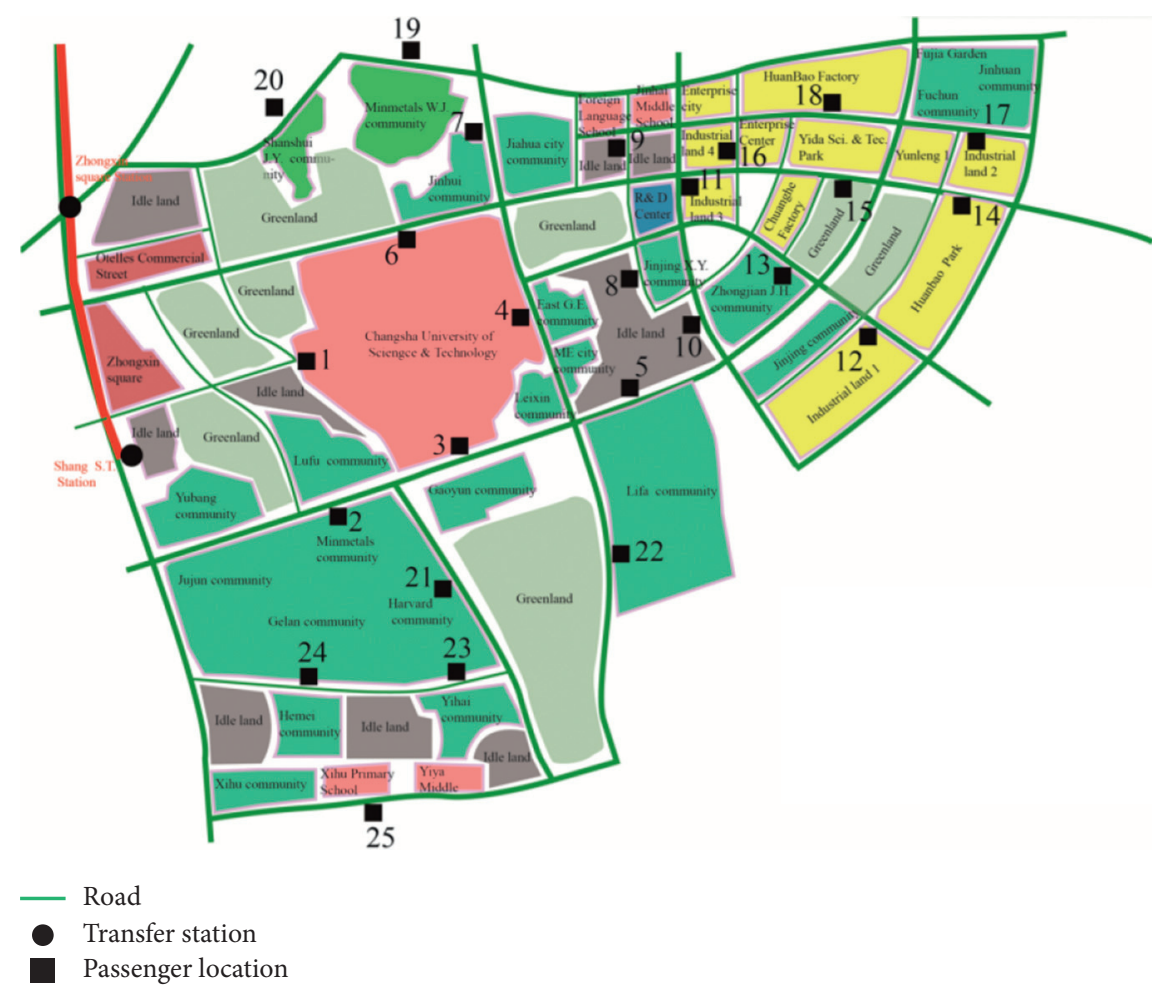

Figure 6: Possible service area and demand point distribution.

If the number of the vehicles is sufficient and the other parameters in the optimal service area are still used, routes and scheduling optimization under pick-up and deliver alone is performed based on the MIP model. The results are shown in Tables 11 and 12 .

From Tables 10 and 12, comparing to the pick-up and deliver alone modes, the advantage of the mixed mode is also obvious: the number of departures, vehicles required, and vehicle mileage required per passenger is reduced by $10.0 \%, 11.1 \%$, and $8 \%$, respectively; average seat utilization rate is increased by $9.5 \%$; system total benefit $E$ is increased by more than 3 times. Compared with Tables 9 and 12, the number of passengers served by HFRFT system is increased by optimizing the service area. Therefore, regardless of whether the RFT system adopts the mixed running mode or alone running mode, the average seat utilization rate and the total system benefit $E$ are improved significantly (as shown in Figure 8). Under the condition of certain transportation capacity, the optimization of service area has certain significance to improve vehicle utilization rate and reduce vehicle idle cost.

\section{Conclusion and Future Work}

This paper proposes a design method for the HFRFT system with multitype vehicles, mixed running, and capacity constraints, where the vehicle routes, scheduling, and service area are optimized according to reservation requirements. A mixed integer programming model and its hybrid of metaheuristic algorithm is devised to efficiently and integrally
Table 4: Coordinates of demand points (miles).

\begin{tabular}{lcc}
\hline Point & $X$ & $Y$ \\
\hline 0 & 0.00 & 0.00 \\
1 & 0.52 & 0.33 \\
2 & 0.66 & -0.16 \\
3 & 1.20 & 0.01 \\
4 & 1.41 & 0.45 \\
5 & 1.72 & 0.17 \\
6 & 0.92 & 0.75 \\
7 & 1.26 & 1.00 \\
8 & 1.77 & 0.60 \\
9 & 1.72 & 1.04 \\
10 & 1.98 & 0.43 \\
11 & 1.88 & 0.89 \\
12 & 2.58 & 0.41 \\
13 & 2.25 & 0.63 \\
14 & 2.79 & 0.86 \\
15 & 2.39 & 0.93 \\
16 & 2.08 & 1.04 \\
17 & 2.85 & 1.08 \\
18 & 2.43 & 1.12 \\
19 & 0.99 & 1.30 \\
20 & 0.60 & 1.13 \\
21 & 1.13 & -0.37 \\
22 & 1.62 & -0.22 \\
23 & 1.13 & -0.76 \\
24 & 0.61 & -0.76 \\
25 & 0.69 & -1.44 \\
\hline & &
\end{tabular}

solve for vehicle routes and scheduling parameters. A heuristic method is also put forward to optimize the service area based on the equilibrium of system supply and demand. 
TABLE 5: Passenger locations and time windows.

\begin{tabular}{|c|c|c|c|c|c|}
\hline Passenger number & Passenger type & Demand point & $L T_{m}$ & $U T_{m}$ & $D T_{m}$ \\
\hline 1 & Pick-up & 1 & $7: 02$ & $7: 07$ & \\
\hline 2 & Pick-up & 1 & $7: 03$ & $7: 08$ & \\
\hline 3 & Pick-up & 1 & $7: 05$ & $7: 10$ & \\
\hline 4 & Pick-up & 1 & $7: 07$ & $7: 12$ & \\
\hline 5 & Pick-up & 1 & $7: 10$ & $7: 15$ & \\
\hline 6 & Pick-up & 1 & $7: 13$ & $7: 18$ & \\
\hline 7 & Pick-up & 1 & $7: 15$ & $7: 20$ & \\
\hline 8 & Pick-up & 1 & $7: 18$ & $7: 23$ & \\
\hline 9 & Pick-up & 1 & $7: 20$ & $7: 25$ & \\
\hline 10 & Pick-up & 1 & $7: 22$ & $7: 27$ & \\
\hline 11 & Pick-up & 1 & $7: 24$ & $7: 29$ & \\
\hline 12 & Pick-up & 1 & $7: 27$ & $7: 32$ & \\
\hline 13 & Deliver & 1 & $7: 30$ & $7: 35$ & $7: 08$ \\
\hline 14 & Deliver & 1 & $7: 40$ & $7: 45$ & $7: 12$ \\
\hline 15 & Deliver & 1 & $7: 45$ & $7: 50$ & $7: 18$ \\
\hline 16 & Pick-up & 1 & $7: 35$ & $7: 40$ & \\
\hline 17 & Pick-up & 1 & $7: 40$ & $7: 45$ & \\
\hline 18 & Pick-up & 2 & $7: 07$ & $7: 12$ & \\
\hline 19 & Pick-up & 2 & $7: 10$ & $7: 15$ & \\
\hline 20 & Pick-up & 2 & $7: 20$ & $7: 25$ & \\
\hline 21 & Pick-up & 2 & $7: 27$ & $7: 32$ & \\
\hline 22 & Deliver & 2 & $7: 33$ & $7: 38$ & $7: 08$ \\
\hline 23 & Deliver & 2 & $7: 40$ & $7: 45$ & $7: 10$ \\
\hline 24 & Pick-up & 3 & $7: 09$ & $7: 14$ & \\
\hline 25 & Pick-up & 3 & $7: 12$ & $7: 17$ & \\
\hline 26 & Pick-up & 3 & $7: 18$ & $7: 23$ & \\
\hline 27 & Pick-up & 3 & $7: 20$ & $7: 25$ & \\
\hline 28 & Pick-up & 3 & $7: 23$ & $7: 28$ & \\
\hline 29 & Pick-up & 3 & $7: 26$ & $7: 31$ & \\
\hline 30 & Pick-up & 3 & $7: 28$ & $7: 33$ & \\
\hline 31 & Pick-up & 3 & $7: 30$ & $7: 35$ & \\
\hline 32 & Pick-up & 3 & $7: 35$ & $7: 40$ & \\
\hline 33 & Pick-up & 3 & $7: 38$ & $7: 42$ & \\
\hline 34 & Pick-up & 3 & $7: 40$ & $7: 45$ & \\
\hline 35 & Pick-up & 3 & $7: 42$ & $7: 47$ & \\
\hline 36 & Deliver & 3 & $7: 30$ & $7: 35$ & $7: 05$ \\
\hline 37 & Deliver & 3 & $7: 40$ & $7: 42$ & $7: 08$ \\
\hline 38 & Pick-up & 4 & $7: 08$ & $7: 13$ & \\
\hline 39 & Pick-up & 4 & $7: 10$ & $7: 15$ & \\
\hline 40 & Pick-up & 4 & $7: 13$ & $7: 18$ & \\
\hline 41 & Pick-up & 4 & $7: 15$ & $7: 20$ & \\
\hline 42 & Pick-up & 4 & $7: 18$ & $7: 23$ & \\
\hline 43 & Pick-up & 4 & $7: 23$ & $7: 28$ & \\
\hline 44 & Pick-up & 4 & $7: 25$ & $7: 30$ & \\
\hline 45 & Pick-up & 4 & $7: 27$ & $7: 32$ & \\
\hline 46 & Pick-up & 4 & $7: 30$ & $7: 35$ & \\
\hline 47 & Pick-up & 4 & $7: 32$ & $7: 37$ & \\
\hline 48 & Pick-up & 4 & $7: 35$ & $7: 40$ & \\
\hline 49 & Pick-up & 4 & $7: 37$ & $7: 42$ & \\
\hline 50 & Pick-up & 4 & $7: 38$ & $7: 43$ & \\
\hline 51 & Pick-up & 4 & $7: 40$ & $7: 45$ & \\
\hline 52 & Deliver & 4 & $7: 45$ & $7: 50$ & $7: 12$ \\
\hline 53 & Pick-up & 5 & $7: 10$ & $7: 15$ & \\
\hline
\end{tabular}


TABle 5: Continued.

\begin{tabular}{|c|c|c|c|c|c|}
\hline Passenger number & Passenger type & Demand point & $L T_{m}$ & $U T_{m}$ & $D T_{m}$ \\
\hline 54 & Pick-up & 5 & $7: 12$ & $7: 17$ & \\
\hline 55 & Pick-up & 5 & $7: 15$ & $7: 20$ & \\
\hline 56 & Pick-up & 5 & $7: 23$ & $7: 28$ & \\
\hline 57 & Pick-up & 5 & $7: 25$ & $7: 30$ & \\
\hline 58 & Pick-up & 5 & $7: 27$ & $7: 32$ & \\
\hline 59 & Pick-up & 5 & $7: 28$ & $7: 33$ & \\
\hline 60 & Pick-up & 5 & $7: 30$ & $7: 35$ & \\
\hline 61 & Pick-up & 5 & $7: 32$ & $7: 37$ & \\
\hline 62 & Pick-up & 5 & $7: 35$ & $7: 40$ & \\
\hline 63 & Pick-up & 5 & $7: 37$ & $7: 42$ & \\
\hline 64 & Deliver & 5 & $7: 35$ & $7: 40$ & $7: 05$ \\
\hline 65 & Deliver & 5 & $7: 38$ & $7: 42$ & $7: 05$ \\
\hline 66 & Deliver & 5 & $7: 42$ & $7: 47$ & $7: 12$ \\
\hline 67 & Deliver & 5 & $7: 50$ & $7: 55$ & $7: 15$ \\
\hline 68 & Pick-up & 6 & $7: 15$ & $7: 20$ & \\
\hline 69 & Pick-up & 6 & $7: 17$ & $7: 22$ & \\
\hline 70 & Pick-up & 6 & $7: 20$ & $7: 25$ & \\
\hline 71 & Pick-up & 6 & $7: 23$ & $7: 28$ & \\
\hline 72 & Pick-up & 6 & $7: 28$ & $7: 33$ & \\
\hline 73 & Deliver & 6 & $7: 30$ & $7: 35$ & $7: 00$ \\
\hline 74 & Deliver & 6 & $7: 35$ & $7: 40$ & $7: 00$ \\
\hline 75 & Pick-up & 7 & $7: 15$ & $7: 20$ & \\
\hline 76 & Pick-up & 7 & $7: 20$ & $7: 25$ & \\
\hline 77 & Deliver & 7 & $7: 35$ & $7: 40$ & $7: 00$ \\
\hline 78 & Deliver & 7 & $7: 40$ & $7: 45$ & $7: 05$ \\
\hline 79 & Pick-up & 8 & $7: 20$ & $7: 25$ & \\
\hline 80 & Pick-up & 8 & $7: 23$ & $7: 28$ & \\
\hline 81 & Pick-up & 8 & $7: 25$ & $7: 30$ & \\
\hline 82 & Pick-up & 9 & $7: 05$ & $7: 10$ & \\
\hline 83 & Pick-up & 9 & $7: 10$ & $7: 15$ & \\
\hline 84 & Pick-up & 9 & $7: 15$ & $7: 20$ & \\
\hline 85 & Pick-up & 10 & $7: 15$ & $7: 20$ & \\
\hline 86 & Pick-up & 10 & $7: 18$ & $7: 23$ & \\
\hline 87 & Pick-up & 10 & $7: 20$ & $7: 25$ & \\
\hline 88 & Deliver & 10 & $7: 25$ & $7: 30$ & $7: 00$ \\
\hline 89 & Deliver & 11 & $7: 45$ & $7: 50$ & $7: 10$ \\
\hline 90 & Deliver & 11 & $7: 45$ & $7: 50$ & $7: 10$ \\
\hline 91 & Pick-up & 12 & $7: 10$ & $7: 15$ & \\
\hline 92 & Pick-up & 12 & $7: 10$ & $7: 15$ & \\
\hline 93 & Deliver & 12 & $7: 35$ & $7: 40$ & $7: 05$ \\
\hline 94 & Deliver & 12 & $7: 35$ & $7: 40$ & $7: 05$ \\
\hline 95 & Pick-up & 13 & $7: 30$ & $7: 35$ & \\
\hline 96 & Pick-up & 13 & $7: 30$ & $7: 35$ & \\
\hline 97 & Deliver & 13 & $7: 35$ & $7: 40$ & $7: 05$ \\
\hline 98 & Pick-up & 14 & $7: 10$ & $7: 15$ & \\
\hline 99 & Pick-up & 14 & $7: 15$ & $7: 20$ & \\
\hline 100 & Deliver & 14 & $7: 35$ & $7: 40$ & $7: 00$ \\
\hline 101 & Deliver & 14 & $7: 35$ & $7: 40$ & $7: 00$ \\
\hline 102 & Deliver & 15 & $7: 40$ & $7: 45$ & $7: 05$ \\
\hline 103 & Deliver & 15 & $7: 40$ & $7: 45$ & $7: 05$ \\
\hline 104 & Pick-up & 16 & $7: 20$ & $7: 25$ & \\
\hline 105 & Pick-up & 16 & $7: 20$ & $7: 25$ & \\
\hline 106 & Pick-up & 17 & $7: 30$ & $7: 35$ & \\
\hline
\end{tabular}


TABle 5: Continued.

\begin{tabular}{|c|c|c|c|c|c|}
\hline Passenger number & Passenger type & Demand point & $L T_{m}$ & $U T_{m}$ & $D T_{m}$ \\
\hline 107 & Pick-up & 17 & $7: 35$ & $7: 40$ & \\
\hline 108 & Deliver & 18 & $7: 35$ & $7: 40$ & $7: 00$ \\
\hline 109 & Deliver & 18 & $7: 40$ & $7: 45$ & $7: 10$ \\
\hline 110 & Deliver & 18 & $7: 40$ & $7: 45$ & $7: 15$ \\
\hline 111 & Pick-up & 19 & $7: 10$ & $7: 15$ & \\
\hline 112 & Pick-up & 19 & $7: 15$ & $7: 20$ & \\
\hline 113 & Pick-up & 19 & $7: 20$ & $7: 25$ & \\
\hline 114 & Pick-up & 19 & $7: 23$ & $7: 28$ & \\
\hline 115 & Pick-up & 19 & $7: 30$ & $7: 35$ & \\
\hline 116 & Pick-up & 19 & $7: 40$ & $7: 45$ & \\
\hline 117 & Pick-up & 20 & $7: 12$ & $7: 17$ & \\
\hline 118 & Pick-up & 20 & $7: 15$ & $7: 20$ & \\
\hline 119 & Pick-up & 20 & $7: 25$ & $7: 30$ & \\
\hline 120 & Pick-up & 20 & $7: 27$ & $7: 32$ & \\
\hline 121 & Pick-up & 20 & $7: 35$ & $7: 40$ & \\
\hline 122 & Pick-up & 20 & $7: 40$ & $7: 45$ & \\
\hline 123 & Pick-up & 21 & $7: 12$ & $7: 17$ & \\
\hline 124 & Pick-up & 21 & $7: 15$ & $7: 20$ & \\
\hline 125 & Pick-up & 21 & $7: 20$ & $7: 25$ & \\
\hline 126 & Pick-up & 21 & $7: 23$ & $7: 28$ & \\
\hline 127 & Pick-up & 21 & $7: 25$ & $7: 30$ & \\
\hline 128 & Pick-up & 21 & $7: 27$ & $7: 32$ & \\
\hline 129 & Pick-up & 21 & $7: 30$ & $7: 35$ & \\
\hline 130 & Pick-up & 21 & $7: 35$ & $7: 40$ & \\
\hline 131 & Pick-up & 21 & $7: 38$ & $7: 43$ & \\
\hline 132 & Deliver & 21 & $7: 35$ & $7: 40$ & $7: 05$ \\
\hline 133 & Deliver & 21 & $7: 40$ & $7: 45$ & $7: 08$ \\
\hline 134 & Pick-up & 22 & $7: 18$ & $7: 23$ & \\
\hline 135 & Pick-up & 22 & $7: 18$ & $7: 23$ & \\
\hline 136 & Pick-up & 22 & $7: 24$ & $7: 29$ & \\
\hline 137 & Pick-up & 22 & $7: 24$ & $7: 29$ & \\
\hline 138 & Pick-up & 22 & $7: 30$ & $7: 35$ & \\
\hline 139 & Pick-up & 23 & $7: 13$ & $7: 18$ & \\
\hline 140 & Pick-up & 23 & $7: 15$ & $7: 20$ & \\
\hline 141 & Pick-up & 23 & $7: 20$ & $7: 25$ & \\
\hline 142 & Pick-up & 23 & $7: 25$ & $7: 30$ & \\
\hline 143 & Pick-up & 23 & $7: 40$ & $7: 45$ & \\
\hline 144 & Deliver & 23 & $7: 35$ & $7: 40$ & $7: 05$ \\
\hline 145 & Deliver & 23 & $7: 40$ & $7: 45$ & $7: 12$ \\
\hline 146 & Pick-up & 24 & $7: 10$ & $7: 15$ & \\
\hline 147 & Pick-up & 24 & $7: 13$ & $7: 18$ & \\
\hline 148 & Pick-up & 24 & $7: 15$ & $7: 20$ & \\
\hline 149 & Pick-up & 24 & $7: 18$ & $7: 23$ & \\
\hline 150 & Pick-up & 24 & $7: 20$ & $7: 25$ & \\
\hline 151 & Pick-up & 24 & $7: 23$ & $7: 28$ & \\
\hline 152 & Pick-up & 24 & $7: 25$ & $7: 30$ & \\
\hline 153 & Pick-up & 24 & $7: 28$ & $7: 32$ & \\
\hline 154 & Pick-up & 24 & $7: 30$ & $7: 35$ & \\
\hline 155 & Deliver & 24 & $7: 35$ & $7: 40$ & $7: 00$ \\
\hline 156 & Deliver & 24 & $7: 42$ & $7: 45$ & $7: 08$ \\
\hline 157 & Deliver & 24 & $7: 45$ & $7: 50$ & $7: 12$ \\
\hline 158 & Pick-up & 25 & $7: 10$ & $7: 15$ & \\
\hline 159 & Pick-up & 25 & $7: 12$ & $7: 17$ & \\
\hline 160 & Pick-up & 25 & $7: 10$ & $7: 15$ & \\
\hline
\end{tabular}




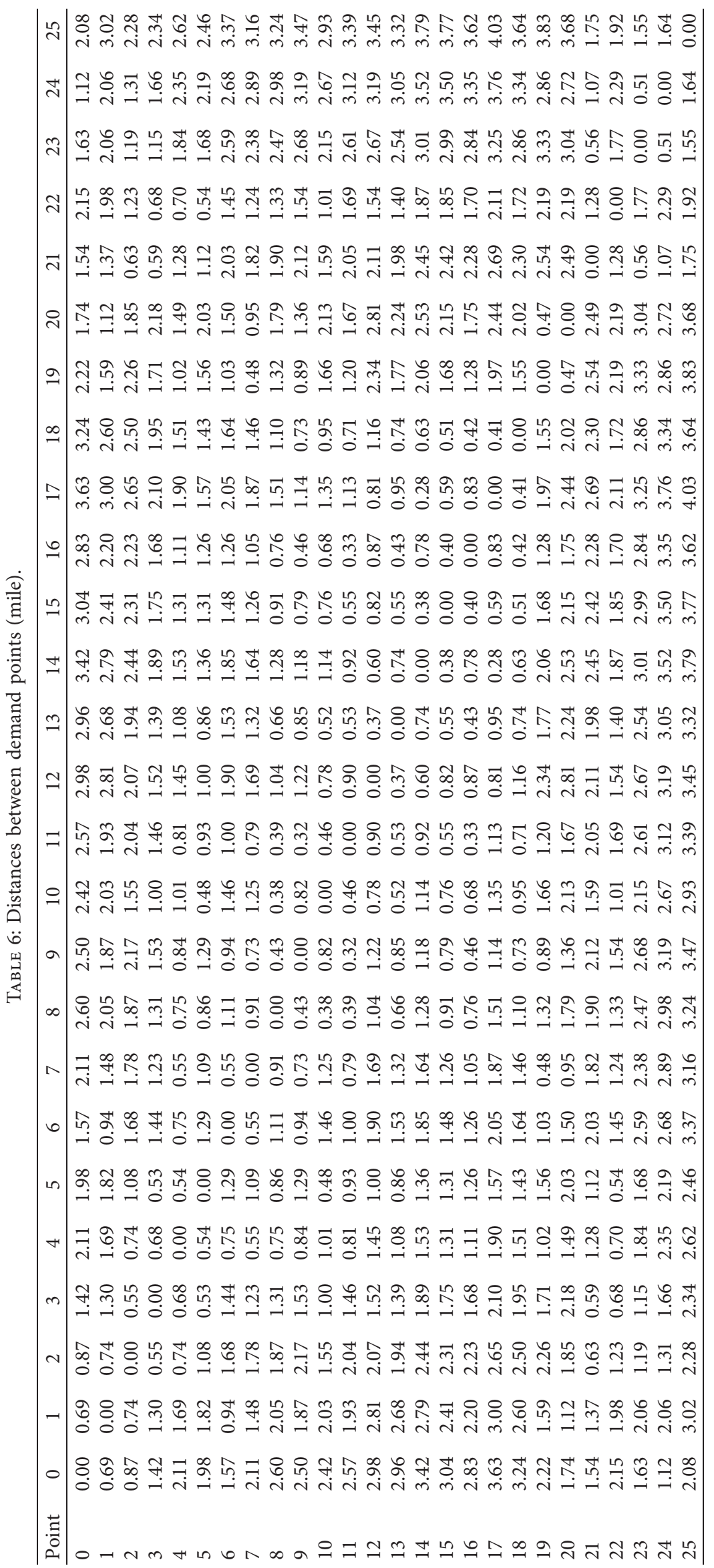


TABLE 7: Optimization results under mixed running mode in the initial service area.

\begin{tabular}{|c|c|c|c|c|c|c|c|}
\hline $\begin{array}{l}\text { Departure } \\
\text { time }\end{array}$ & $\begin{array}{l}\text { Vehicle } \\
\text { number }\end{array}$ & Route & $\begin{array}{c}\text { Mileage } \\
\text { (miles) }\end{array}$ & $\begin{array}{c}\text { Cumulative number of } \\
\text { passengers serviced }\end{array}$ & $\begin{array}{c}\text { Seat } \\
\text { utilization }\end{array}$ & $\begin{array}{l}\text { End } \\
\text { time }\end{array}$ & $\begin{array}{l}\text { Running } \\
\text { mode }\end{array}$ \\
\hline $7: 13$ & $M_{21}$ & $\begin{array}{c}0-68-69-1-3-6-9-25-27-38- \\
39-40-43-29-45-19-0\end{array}$ & 7.45 & 15 & 100 & $7: 33$ & $\begin{array}{l}\text { Alone pick- } \\
\text { up }\end{array}$ \\
\hline $7: 14$ & $M_{11}$ & $\begin{array}{c}0-26-18-5-70-41-44-42- \\
24-46-21-0\end{array}$ & 7.37 & 10 & 100 & $7: 36$ & $\begin{array}{l}\text { Alone pick- } \\
\text { up }\end{array}$ \\
\hline $7: 30$ & $M_{22}$ & $\begin{array}{c}0-13-11-10-71-72-73-47- \\
30-32-48-49-51-35-0\end{array}$ & 5.85 & 13 & 86.6 & $7: 47$ & Mixed \\
\hline $7: 35$ & $M_{12}$ & $\begin{array}{c}0-8-4-7-20-22-34-28-31- \\
33-36-50-74-0\end{array}$ & 4.99 & 12 & 120 & $7: 49$ & Mixed \\
\hline $7: 45$ & $M_{11}$ & $\begin{array}{c}0-23-52-37-12-14-2-15- \\
16-17-0\end{array}$ & 4.28 & 9 & 90 & $7: 57$ & Mixed \\
\hline
\end{tabular}

Table 8: Optimization results under pick-up and deliver alone in the initial service area.

\begin{tabular}{|c|c|c|c|c|c|c|c|}
\hline $\begin{array}{l}\text { Departure } \\
\text { time }\end{array}$ & $\begin{array}{l}\text { Vehicle } \\
\text { number }\end{array}$ & Route & $\begin{array}{l}\text { Mileage } \\
\text { (miles) }\end{array}$ & $\begin{array}{c}\text { Cumulative number of } \\
\text { passengers serviced }\end{array}$ & $\begin{array}{c}\text { Seat } \\
\text { utilization }\end{array}$ & $\begin{array}{l}\text { End } \\
\text { time }\end{array}$ & $\begin{array}{c}\text { Running } \\
\text { mode }\end{array}$ \\
\hline $7: 03$ & $M_{21}$ & $\begin{array}{c}0-3-9-20-24-25-26-28- \\
39-42-44-19-0\end{array}$ & 4.28 & 11 & 73.3 & $7: 30$ & $\begin{array}{l}\text { Alone pick- } \\
\text { up }\end{array}$ \\
\hline $7: 13$ & $M_{11}$ & $\begin{array}{c}0-1-2-4-5-6-7-53-40- \\
38-18-0\end{array}$ & 3.94 & 10 & 100 & $7: 24$ & $\begin{array}{l}\text { Alone pick- } \\
\text { up }\end{array}$ \\
\hline $7: 18$ & $M_{12}$ & $\begin{array}{c}0-58-59-13-14-15-22- \\
23-36-37-52-0\end{array}$ & 6.58 & 10 & 100 & $7: 37$ & $\begin{array}{l}\text { Alone } \\
\text { deliver }\end{array}$ \\
\hline $7: 18$ & $M_{13}$ & $\begin{array}{c}0-54-56-8-10-11-21- \\
41-43-45-27-0\end{array}$ & 6.09 & 10 & 100 & $7: 36$ & $\begin{array}{l}\text { Alone pick- } \\
\text { up }\end{array}$ \\
\hline $7: 28$ & $M_{14}$ & $\begin{array}{c}0-57-46-47-48-55-12- \\
16-17-0\end{array}$ & 4.70 & 8 & 80 & $7: 41$ & $\begin{array}{l}\text { Alone pick- } \\
\text { up }\end{array}$ \\
\hline $7: 36$ & $M_{11}$ & $\begin{array}{c}0-29-30-31-32-34-49- \\
50-51-33-35-0\end{array}$ & 4.21 & 10 & 100 & $7: 48$ & $\begin{array}{l}\text { Alone pick- } \\
\text { up }\end{array}$ \\
\hline
\end{tabular}

TABLE 9: Comparisons of two running modes in the initial service area.

\begin{tabular}{|c|c|c|c|c|c|c|c|}
\hline \multirow[t]{2}{*}{ Running mode } & \multirow[t]{2}{*}{$K$} & \multicolumn{3}{|c|}{$\begin{array}{l}\text { Number of vehicles } \\
\text { required }\end{array}$} & \multirow[t]{2}{*}{ Average seat utilization rate } & \multirow[t]{2}{*}{ Vehicle mileage required per passenger(miles) } & \multirow[t]{2}{*}{$E(\$)$} \\
\hline & & $v=1$ & $v=2$ & Sum & & & \\
\hline Alone & 6 & 4 & 1 & 5 & $90.76 \%$ & 0.51 & -59.0 \\
\hline Mixed & 5 & 2 & 2 & 4 & $98.33 \%$ & 0.51 & 14.5 \\
\hline Increase rate $(\%)$ & -16.7 & - & - & -20 & 8.3 & - & - \\
\hline
\end{tabular}

Case studies show that the mixed running mode with multitype vehicle can significantly increase the seat utilization and consequentially reduce the vehicle ownership and average vehicle travel distance per passenger significantly. From the case studies, the following conclusions are obtained:

(i) The MIP model can optimize the running route and departure time of each shift under reservation requirements with the mixed running, multitype vehicles, and capacity constraints and also optimize the number of departures and vehicle possession.

(ii) In the same situation of reservation requirements, the mixed running mode can significantly improve the seat utilization rate compared with that of the pick-up and deliver alone modes. It can also significantly reduce the total system cost, number of vehicle ownership and departures, and vehicle running mileage required per passenger. The results indicated that the mixed running mode is superior.

(iii) The proposed service area heuristic optimization method based on the MIP model for HFRFT running routes and scheduling coordination model can determine an optimal service area that matches the capacity with the demand.

The optimization design method can provide certain practical guidance for the transit operators to determine the operation strategy and also contribute to the promotion and implementation of the RFT technology. In this study, we focus on reservation requirements. In real world, passengers may make a pick-up or deliver request during the running of 


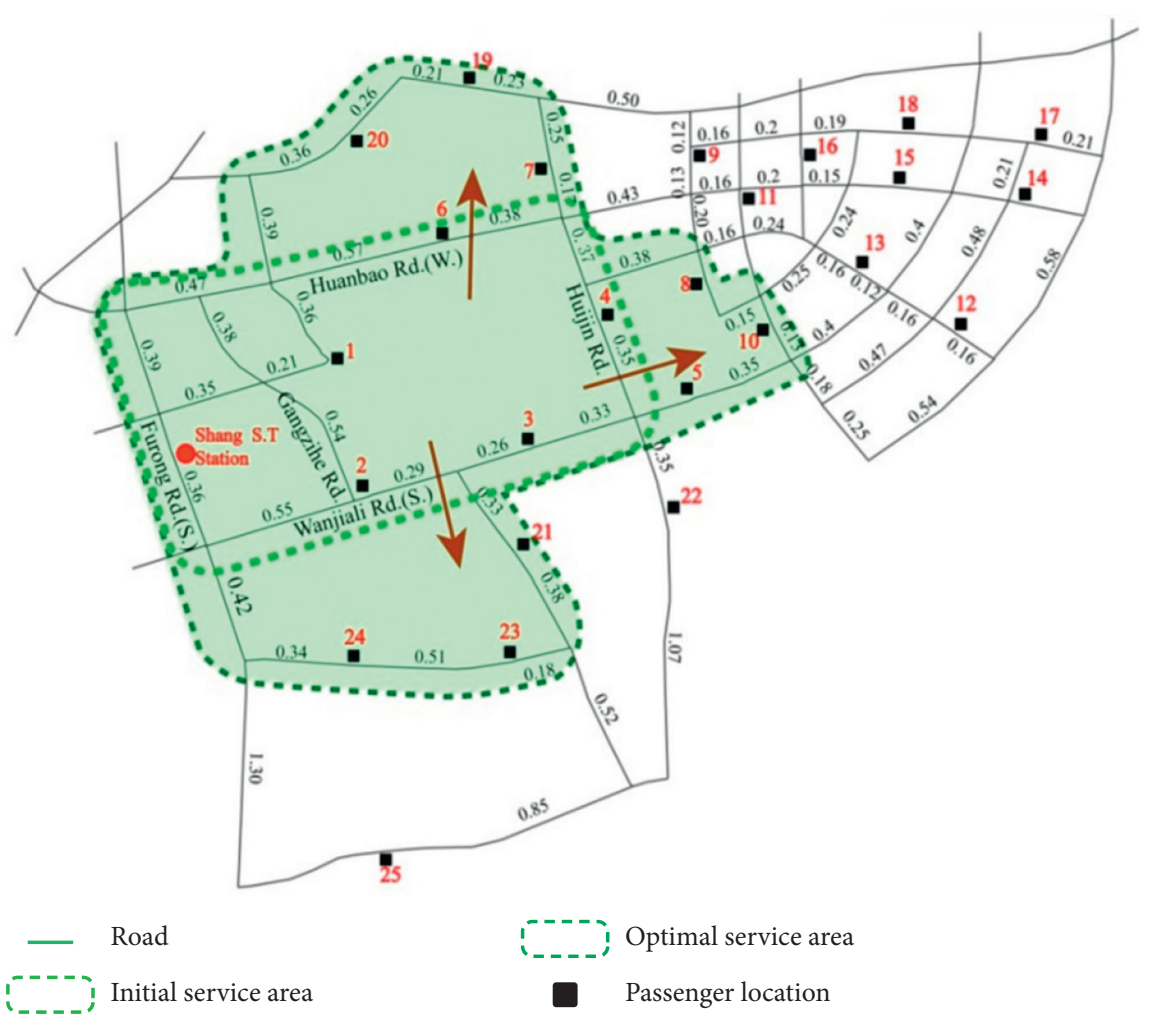

FigURE 7: Service area optimization process.

TABLE 10: Optimization results under mixed running in the optimal service area.

\begin{tabular}{|c|c|c|c|c|c|c|c|}
\hline $\begin{array}{l}\text { Departure } \\
\text { time }\end{array}$ & $\begin{array}{l}\text { Vehicle } \\
\text { number }\end{array}$ & Route & $\begin{array}{l}\text { Mileage } \\
\text { (miles) }\end{array}$ & $\begin{array}{c}\text { Cumulative number of } \\
\text { passengers serviced }\end{array}$ & $\begin{array}{c}\text { Seat } \\
\text { utilization }\end{array}$ & $\begin{array}{l}\text { End } \\
\text { time }\end{array}$ & $\begin{array}{c}\text { Running } \\
\text { mode }\end{array}$ \\
\hline $7: 09$ & $M_{11}$ & $\begin{array}{c}0-111-112-76-68-70-41-42-28- \\
124-127-0\end{array}$ & 6.81 & 10 & 100 & $7: 32$ & $\begin{array}{l}\text { Alone pick- } \\
\text { up }\end{array}$ \\
\hline $7: 10$ & $M_{21}$ & $\begin{array}{c}0-139-140-123-39-20-4-5-128- \\
119-143-141-0\end{array}$ & 13.49 & 11 & 73.3 & $7: 48$ & $\begin{array}{l}\text { Alone pick- } \\
\text { up }\end{array}$ \\
\hline $7: 14$ & $M_{22}$ & $0-113-7-118-75-27-29-12-116-0$ & 12.17 & 8 & 53.3 & $7: 47$ & $\begin{array}{l}\text { Alone } \\
\text { deliver }\end{array}$ \\
\hline $7: 16$ & $M_{23}$ & $\begin{array}{c}0-2-3-8-10-146-148-126-26-31- \\
121-16-0\end{array}$ & 8.41 & 11 & 73.3 & $7: 43$ & $\begin{array}{l}\text { Alone pick- } \\
\text { up }\end{array}$ \\
\hline $7: 22$ & $M_{12}$ & $\begin{array}{c}0-1-6-9-11-18-24-25-142-151- \\
153-0\end{array}$ & 4.77 & 10 & 100 & $7: 35$ & $\begin{array}{l}\text { Alone pick- } \\
\text { up }\end{array}$ \\
\hline $7: 30$ & $M_{13}$ & $\begin{array}{c}0-13-19-38-40-43-44-46-114- \\
115-69-71-0\end{array}$ & 5.80 & 11 & 110 & $7: 46$ & Mixed \\
\hline $7: 30$ & $M_{14}$ & $\begin{array}{c}0-30-36-129-45-47-48-49-50-32- \\
33-34-0\end{array}$ & 5.39 & 11 & 110 & $7: 45$ & Mixed \\
\hline $7: 40$ & $M_{15}$ & $\begin{array}{c}0-72-73-74-77-78-117-120-122- \\
51-130-131-145-147-150-154-0\end{array}$ & 8.03 & 15 & 150 & $8: 02$ & Mixed \\
\hline $7: 45$ & $M_{13}$ & $\begin{array}{l}0-14-15-125-132-133-144-152- \\
155-156-157-149-35-37-52-21- \\
22-23-17-0\end{array}$ & 7.66 & 18 & 120 & $8: 07$ & Mixed \\
\hline
\end{tabular}


TABLE 11: Optimization results under pick-up and deliver alone in the optimal service area.

\begin{tabular}{|c|c|c|c|c|c|c|c|}
\hline $\begin{array}{l}\text { Departure } \\
\text { time }\end{array}$ & $\begin{array}{l}\text { Vehicle } \\
\text { number }\end{array}$ & Route & $\begin{array}{l}\text { Mileage } \\
\text { (miles) }\end{array}$ & $\begin{array}{l}\text { Cumulative number of } \\
\text { passengers serviced }\end{array}$ & $\begin{array}{c}\text { Seat utilization } \\
(\%)\end{array}$ & $\begin{array}{l}\text { End } \\
\text { time }\end{array}$ & $\begin{array}{l}\text { Running } \\
\text { mode }\end{array}$ \\
\hline $7: 07$ & $M_{11}$ & $\begin{array}{c}0-19-41-38-39-24-25-95- \\
76-28-21-0\end{array}$ & 7.04 & 10 & 100 & $7: 31$ & $\begin{array}{l}\text { Alone pick- } \\
\text { up }\end{array}$ \\
\hline $7: 10$ & $M_{12}$ & $\begin{array}{c}0-71-40-77-94-97-99-44- \\
45-46-0\end{array}$ & 10.06 & 9 & 90 & $7: 38$ & $\begin{array}{l}\text { Alone pick- } \\
\text { up }\end{array}$ \\
\hline $7: 10$ & $M_{21}$ & $\begin{array}{c}0-53-60-20-96-98-88-78- \\
90-80-79-101-89-102\end{array}$ & 10.61 & 13 & 86.6 & $7: 40$ & $\begin{array}{l}\text { Alone } \\
\text { deliver }\end{array}$ \\
\hline $7: 12$ & $M_{13}$ & $\begin{array}{c}0-13-14-85-86-92-93- \\
103-104-105-0\end{array}$ & 4.26 & 9 & 90 & $7: 24$ & $\begin{array}{l}\text { Alone } \\
\text { deliver }\end{array}$ \\
\hline $7: 16$ & $M_{22}$ & $\begin{array}{c}0-64-65-66-67-61-54-55- \\
56-2-3-4-6-12-0\end{array}$ & 4.44 & 13 & 86.6 & $7: 30$ & $\begin{array}{l}\text { Alone pick- } \\
\text { up }\end{array}$ \\
\hline $7: 18$ & $M_{14}$ & $\begin{array}{c}0-58-59-36-37-22-23-52- \\
62-63-15-0\end{array}$ & 7.02 & 10 & 100 & $7: 38$ & $\begin{array}{l}\text { Alone } \\
\text { deliver }\end{array}$ \\
\hline $7: 18$ & $M_{15}$ & $\begin{array}{c}0-5-7-8-9-26-27-87-70- \\
72-74-0\end{array}$ & 7.95 & 10 & 100 & $7: 41$ & $\begin{array}{l}\text { Alone pick- } \\
\text { up }\end{array}$ \\
\hline $7: 20$ & $M_{23}$ & $\begin{array}{c}0-1-10-42-73-84-34-43- \\
47-49-91-100-0\end{array}$ & 11.10 & 11 & 73.3 & $7: 52$ & $\begin{array}{l}\text { Alone pick- } \\
\text { up }\end{array}$ \\
\hline $7: 22$ & $M_{16}$ & $\begin{array}{c}0-11-18-29-57-68-16-75- \\
69-50-51-0\end{array}$ & 10.75 & 10 & 100 & $7: 52$ & $\begin{array}{l}\text { Alone pick- } \\
\text { up }\end{array}$ \\
\hline $7: 30$ & $M_{13}$ & $\begin{array}{c}0-81-82-83-30-31-32-33- \\
48-35-17-0\end{array}$ & 5.49 & 10 & 100 & $7: 48$ & $\begin{array}{l}\text { Alone pick- } \\
\text { up }\end{array}$ \\
\hline
\end{tabular}

TABLe 12: Comparisons of two running modes in the optimal service area.

\begin{tabular}{lccccccc}
\hline \multirow{2}{*}{ Running mode } & $K$ & \multicolumn{3}{c}{$\begin{array}{c}\text { Number of vehicles } \\
\text { required }\end{array}$} & Average seat utilization rate & Vehicle mileage required per passenger(miles) & $E(\$)$ \\
\hline Alone & 10 & 6 & 3 & 9 & $91.3 \%$ & 0.75 & 23.1 \\
Mixed & 9 & 5 & 3 & 8 & $100 \%$ & 0.69 & 119.3 \\
Increase rate (\%) & -10.0 & - & - & -11.1 & 9.5 & -8.0 & 416 \\
\hline
\end{tabular}

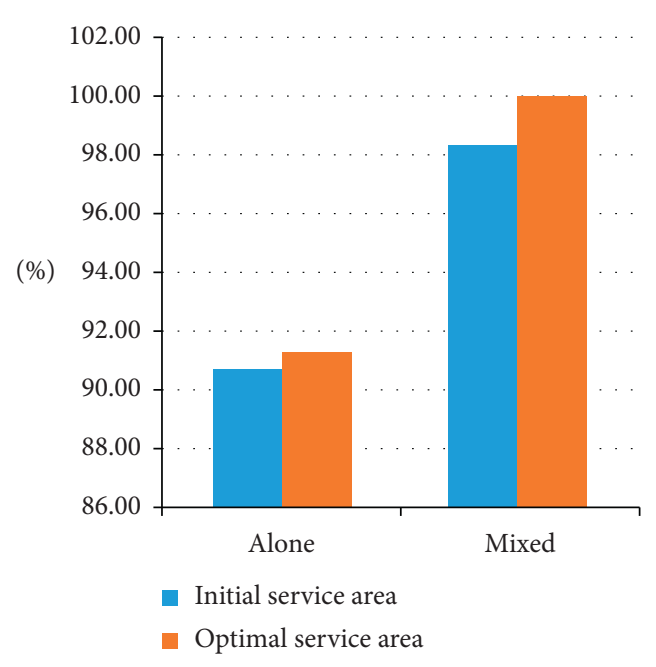

(a)

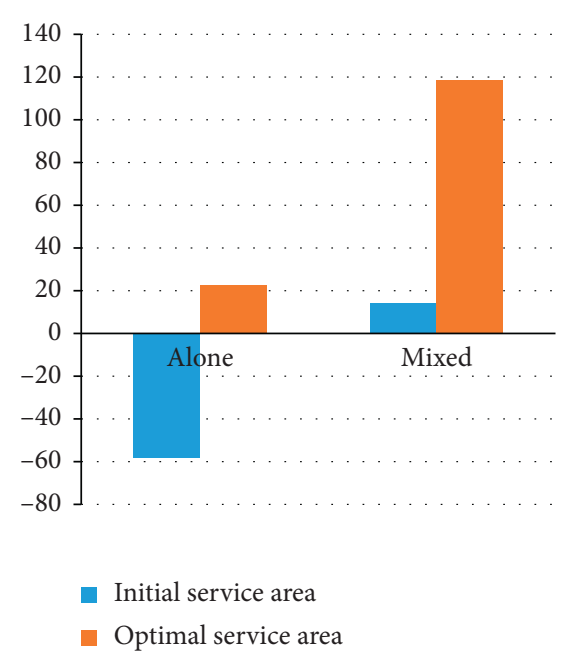

(b)

FIgURE 8: Comparisons of two operation modes before and after optimization. (a) Comparisons of average seat utilization. (b) Comparisons of number of vehicles required. 
the vehicle, which means it will be more practical to consider the real-time requirements. In addition, the travel time of each road section is not a fixed value, it changes with the different traffic flow. Therefore, future research will focus on designing HFRFT system under the mixed demand (with reservation and real-time requirements at the same time) and dynamic road network.

\section{Data Availability}

The data used to support the findings of this study are available from the corresponding author upon request.

\section{Conflicts of Interest}

The authors declare that there are no conflicts of interest regarding the publication of this paper.

\section{Acknowledgments}

This research was funded by the National Natural Science Foundation of China (No. 51678075). In addition, this work was also supported by the Hunan Key Area R\&D Program (2019SK2171) and Hunan Key Laboratory of Smart Roadway and Cooperative Vehicle-Infrastructure Systems (2017TP1016). In addition, this work was also supported by the Hunan Provincial Natural Science Foundation of China (No. 2019JJ30026), the Young Elite Scientists Sponsorship Program by Hunan Province of China (2018RS3074), the Young Elite Scientists Sponsorship Program by Hunan Provincial Department of Education (18B142), Changsha Science and Technology Bureau Project (kq1801056), Open Fund of Hunan Key Laboratory of Smart Roadway and Cooperative Vehicle-Infrastructure Systems (kfj180702; kfj190702; kfj190704; and 180402), Innovation Team Project for Transportation Engineering in CSUST, CSUST International Cooperation Project (2019IC11), and Ministry of Science Project with Montenegro (3-2).

\section{References}

[1] T. Liu and A. Ceder, "Analysis of a new public-transportservice concept: customized bus in China," Transport Policy, vol. 39, pp. 63-76, 2015.

[2] C. Ma, W. Hao, A. Wang, and H. Zhao, "Developing a coordinated signal control system for urban ring road under the vehicle-infrastructure connected environment," IEEE Access, vol. 6, pp. 52471-52478, 2018.

[3] C. Ma, W. Hao, W. Xiang, and W. Yan, "The impact of aggressive driving behavior on driver-injury severity at highway-rail grade crossings accidents," Journal of Advanced Transportation, vol. 2018, Article ID 9841498, 10 pages, 2018.

[4] Y. Li, W. Chen, S. Peeta, and Y. Wang, "Platoon control of connected multi-vehicle systems under V2X communications: design and experiments," IEEE Transactions on Intelligent Transportation Systems, vol. 21, no. 5, pp. 1891-1902, 2020.

[5] L. Hu, X. Hu, J. Wan, M. Lin, and J. Huang, "The injury epidemiology of adult riders in vehicle-two-wheeler crashes in
China, Ningbo, 2011-2015," Journal of Safety Research, vol. 72, pp. 21-28, 2020.

[6] L. Hu, J. Ou, J. Huang, Y. Chen, and D. Cao, "A review of research on traffic conflicts based on intelligent vehicles," IEEE Access, vol. 8, pp. 24471-24483, 2020.

[7] K.Y. Ma, S. Chen, A. J. Khattak, and Y. Pan, "On-line aggressive driving identification based on in-vehicle kinematic parameters under naturalistic driving conditions," Transportation Research Part C: Emerging Technologies, vol. 114, pp. 554-571, 2020.

[8] X. Li and L. Quadrifoglio, "Feeder transit services: choosing between fixed and demand responsive policy," Transportation Research Part C: Emerging Technologies, vol. 18, no. 5, pp. 770-780, 2010.

[9] Y. S. Sun, Q. W. Guo, P. Schonfeld, and Z. F. Li, "Evolution of public transit modes in a commuter corridor," Transportation Research Part C: Emerging Technologies, vol. 75, pp. 84-102, 2017.

[10] Q.-W. Guo, J. Y. J. Chow, and P. Schonfeld, "Stochastic dynamic switching in fixed and flexible transit services as market entry-exit real options," Transportation Research Procedia, vol. 23, pp. 380-399, 2017.

[11] M. Saberi and İ. Ö. Verbas, "Continuous approximation model for the vehicle routing problem for emissions minimization at the strategic level," Journal of Transportation Engineering, vol. 138, no. 11, pp. 1368-1376, 2012.

[12] Y. Yan, Z. Liu, Q. Meng, and Y. Jiang, "Robust optimization model of bus transit network design with stochastic travel time," Journal of Transportation Engineering, vol. 139, no. 6, pp. 625-634, 2013.

[13] Y. Yao, B. M. Randy, and X. Chi, "Demand-responsive transit circulator service network design," Transportation Research Part E, vol. 76, pp. 160-175, 2015.

[14] M. Dessouky, M. Rahimi, and M. Weidner, "Jointly optimizing cost, service, and environmental performance in demand-responsive transit scheduling," Transportation Research Part D: Transport and Environment, vol. 8, no. 6, pp. 433-465, 2003.

[15] S. Pan, J. Yu, X. Yang et al., "Designing a flexible feeder transit system serving irregularly shaped and gated communities: determining service area and feeder route planning," Journal of Urban Planning and Development, vol. 141, no. 3, Article ID 04014028, 2015.

[16] A. Núñez, C. E. Cortés, D. Sáez, B. De Schutter, and M. Gendreau, "Multiobjective model predictive control for dynamic pickup and delivery problems," Control Engineering Practice, vol. 32, pp. 73-86, 2014.

[17] S. F. Ghannadpour, S. Noori, R. Tavakkoli-Moghaddam, and K. Ghoseiri, "A multi-objective dynamic vehicle routing problem with fuzzy time windows: model, solution and application," Applied Soft Computing, vol. 14, no. 1, pp. 504-527, 2014.

[18] M. Schilde, K. F. Doerner, and R. F. Hartl, "Integrating stochastic time-dependent travel speed in solution methods for the dynamic dial-a-ride problem," European Journal of Operational Research, vol. 238, no. 1, pp. 18-30, 2014.

[19] D. Kirchler and R. Wolfler Calvo, "A granular tabu search algorithm for the dial-a-ride problem," Transportation Research Part B: Methodological, vol. 56, no. 10, pp. 120-135, 2013.

[20] B. Sun, M. Wei, and S. L. Zhu, "Optimal design of demandresponsive feeder transit services with passengers' multiple time windows and satisfaction," Future Internet, vol. 30, pp. 1-15, 2018. 
[21] J. Tang, Y. Wang, W. Hao, F. Liu, H. Huang, and Y. Wang, “A mixed path size logit-based taxi customer-search model considering spatio-temporal factors in route choice," IEEE Transactions on Intelligent Transportation Systems, vol. 21, no. 4, pp. 1347-1358, 2019.

[22] M. M. Aldaihani, L. Quadrifoglio, M. M. Dessouky, and R. Hall, "Network design for a grid hybrid transit service," Transportation Research Part A: Policy and Practice, vol. 38, no. 7, pp. 511-530, 2004.

[23] J.-B. Sheu, "A fuzzy clustering approach to real-time demandresponsive bus dispatching control," Fuzzy Sets and Systems, vol. 150, no. 3, pp. 437-455, 2005.

[24] M. Rahimi, M. Amirgholy, and E. J. Gonzales, "System modeling of demand responsive transportation services: evaluating cost efficiency of service and coordinated taxi usage," Transportation Research Part E: Logistics and Transportation Review, vol. 112, pp. 66-83, 2018.

[25] P. Chen and Y. Nie, "Optimal design of demand adaptive paired-line hybrid transit: case of radial route structure," Transportation Research Part E: Logistics and Transportation Review, vol. 110, pp. 71-89, 2018.

[26] F. Qiu, W. Li, and J. Zhang, "A dynamic station strategy to improve the performance of flex-route transit services," Transportation Research Part C: Emerging Technologies, vol. 48, pp. 229-240, 2014.

[27] B. Alshalalfah and A. Shalaby, "Development of important relationships for the planning of flex-route transit services," in Proceedings of Transportation Research Board 89th Annual Meeting, pp. 1-21, Washington DC, USA, 2010.

[28] S. M. Nourbakhsh and Y. Ouyang, "A structured flexible transit system for low demand areas," Transportation Research Part B: Methodological, vol. 46, no. 1, pp. 204-216, 2012.

[29] B. Alshalalfah and A. Shalaby, "Feasibility of flex-route as a feeder transit service to rail stations in the suburbs: case study in Toronto," Journal of Urban Planning and Development, vol. 138, no. 1, pp. 90-100, 2012.

[30] S. Chandra and L. Quadrifoglio, "A model for estimating the optimal cycle length of demand responsive feeder transit services," Transportation Research Part B: Methodological, vol. 51, no. 2, pp. 1-16, 2013.

[31] S. Chandra and L. Quadrifoglio, "A new street connectivity indicator to predict performance for feeder transit services," Transportation Research Part C: Emerging Technologies, vol. 30, no. 3, pp. 67-80, 2013.

[32] D. Edwards and K. Watkins, "Comparing fixed-route and demand-responsive feeder transit systems in real-world settings," Transportation Research Record: Journal of the Transportation Research Board, vol. 2352, no. 1, pp. 128-135, 2013.

[33] R. Kelly, N. Ronald, and M. Wallace, "Exploring the effects of mixed request schemes for demand-responsive feeder services," in Proceedings of 21st International Congress on Modeling and Simulation, pp. 1731-1737, Gold Coast, Australia, November 2015.

[34] M. V. Engelen, O. Cats, and H. Post, "Enhancing flexible transport services with demand-anticipatory insertion heuristics," Transportation Research Part E, vol. 110, no. 1, pp. 110-121, 2018.

[35] C. Frei, M. Hyland, and H. S. Mahmassani, "Flexing service schedules: assessing the potential for demand-adaptive hybrid transit via a stated preference approach," Transportation Research Part C: Emerging Technologies, vol. 76, pp. 71-89, 2017.
[36] A. Gschwender, S. Jara-Díaz, and C. Bravo, "Feeder-trunk or direct lines? economies of density, transfer costs and transit structure in an urban context," Transportation Research Part A: Policy and Practice, vol. 88, pp. 209-222, 2016.

[37] S. Kikuchi and R. A. Donnelly, "Scheduling demand-responsive transportation vehicles using fuzzy-set theory," Journal of Transportation Engineering, vol. 118, no. 3, pp. 391-409, 1992.

[38] S. C. Hsu, "Determinants of passenger transfer waiting time at multi-modal connecting stations," Transportation Research Part E: Logistics and Transportation Review, vol. 46, no. 3, pp. 404-413, 2010.

[39] R. Nair and E. Miller-Hooks, "Equilibrium network design of shared-vehicle systems," European Journal of Operational Research, vol. 235, no. 1, pp. 47-61, 2014.

[40] X. Lu, J. Yu, X. Yang, S. Pan, and N. Zou, "Flexible feeder transit route design in complexroad network," Journal of Transportation Systems Engineering and Information Technology, vol. 16, no. 6, pp. 128-134, 2016.

[41] X. Lu, J. Yu, X. Yang, S. Pan, and N. Zou, "Flexible feeder transit route design to enhance service accessibility in urban area," Journal of Advanced Transportation, vol. 50, no. 4, pp. 507-521, 2016.

[42] Y. Zheng, W. Li, and F. Qiu, "A slack arrival strategy to promote flex-route transit services," Transportation Research Part C: Emerging Technologies, vol. 92, pp. 442-455, 2018.

[43] J. Tang, Y. Yang, and Y. Qi, "A hybrid algorithm for urban transit schedule optimization," Physica A: Statistical Mechanics and Its Applications, vol. 512, pp. 745-755, 2018.

[44] Y. Guo, J. Ma, C. Xiong, X. Li, F. Zhou, and W. Hao, "Joint optimization of vehicle trajectories and intersection controllers with connected automated vehicles: combined dynamic programming and shooting heuristic approach," Transportation Research Part C: Emerging Technologies, vol. 98, pp. 54-72, 2019.

[45] S. Chandra and L. Quadrifoglio, "Critical street links for demand responsive feeder transit services," Computers \& Industrial Engineering, vol. 66, no. 3, pp. 584-592, 2013.

[46] M. Dessouky and S. Adam, "Real-time schedulingrules for demand responsive transit systems," in Proceedings of 1998 IEEE International Conference on Systems, Man, and Cybernetics, vol. 3, pp. 2956-2961, San Diego, CA, USA, October 1998.

[47] J. Zhao and M. Dessouky, "Service capacity design problems for mobility allowance shuttle transit systems," Transportation Research Part B: Methodological, vol. 42, no. 2, pp. 135-146, 2008.

[48] X. G. Li and L. Quadrifoglio, "Optimal zone design for feeder transit services," Transportation Research Record: Journal of the Transportation Research Board, vol. 2111, no. 1, pp. 100108, 2009.

[49] F. Errico, T. G. Crainic, F. Malucelli, and M. Nonato, "A survey on planning semi-flexible transit systems: methodological issues and a unifying framework," Transportation Research Part C: Emerging Technologies, vol. 36, pp. 324-338, 2013.

[50] X. Li and L. Quadrifoglio, "2-vehicle zone optimal design for feeder transit services," Public Transport, vol. 3, no. 1, pp. 89-104, 2011.

[51] L. Quadrifoglio, M. M. Dessouky, and F. Ordóñez, “Mobility allowance shuttle transit (MAST) services: MIP formulation and strengthening with logic constraints," European Journal of Operational Research, vol. 185, no. 2, pp. 481-494, 2008.

[52] L. Quadrifoglio, M. M. Dessouky, and F. Ordóñez, "A simulation study of demand responsive transit system design," 
Transportation Research Part A: Policy and Practice, vol. 42, no. 4, pp. 718-737, 2008.

[53] L. Quadrifoglio and X. Li, "A methodology to derive the critical demand density for designing and operating feeder transit services," Transportation Research Part B: Methodological, vol. 43, no. 10, pp. 922-935, 2009.

[54] S. M. M. Amiripour, A. Ceder, and A. S. Mohaymany, "Designing large-scale bus network with seasonal variations of demand," Transportation Research Part C, vol. 48, pp. 332-338, 2014.

[55] A. Pratelli and F. Schoen, "A mathematical programming model for the bus deviation route problem," Journal of the Operational Research Society, vol. 52, no. 5, pp. 494-502, 2001.

[56] I. Razi and G. U. Muhammad, "Intelligent bus stops in the flexible bus systems," Journal of Engineering Science and Technology Review, vol. 7, no. 4, pp. 59-65, 2014.

[57] J. Jaeyoung, R. Jayakrishnan, and D. Nam, "High coveragepoint-point transit: hybrid evolutionary approach to local vehicle routing," KSCE Journal of Civil Engineering, vol. 19, no. 6, pp. 1882-1891, 2015

[58] S. Chandra, M. E. Bari, P. C. Devarasetty, and S. Vadali, "Accessibility evaluations of feeder transit services," Transportation Research Part A: Policy and Practice, vol. 52, pp. 47-63, 2013.

[59] A. Ceder, "Optimal multi-vehicle type transit timetabling and vehicle scheduling," Procedia-Social and Behavioral Sciences, vol. 20, pp. 19-30, 2011.

[60] P. C. Guedes and D. Borenstein, "Real-time multi-depot vehicle type rescheduling problem," Transportation Research Part B: Methodological, vol. 108, pp. 217-234, 2018.

[61] Z. W. Wang, T. Chen, and M. Q. Song, "Coordination optimization of operating lines and scheduling for Responsive Feeder Transit under the mixed operation mode," Journal of Traffic and Transportation Engineering, vol. 19, no. 5, pp. 1-9, 2019.

[62] C. P. Chen, S. J. Han, J. S. Lu et al., "A multi-chromosome Genetic algorithm for multi-depot and multi-type vehicle routing problems," China Mechanical Engineering, vol. 29, no. 2, pp. 218-223, 2018.

[63] M. Wei, T. Liu, B. Sun, and B. Jing, "Optimal integrated model for feeder transit route design and frequency-setting problem with stop selection," Journal of Advanced Transportation, vol. 2020, pp. 1-12, 2020.

[64] Z. Wang, J. Yu, W. Hao et al., "Two-step coordinated optimization model of mixed demand responsive feeder transit," Journal of Transportation Engineering, Part A: Systems, vol. 146, no. 3, Article ID 04019082, 2020.

[65] L. Ahmed, C. Mumford, and A. Kheiri, "Solving urban transit route design problem using selection hyper-heuristics," European Journal of Operational Research, vol. 274, no. 2, pp. 545-559, 2019.

[66] W. Hao, Y. Lin, Y. Cheng, and X. Yang, "Signal progression model for long arterial: intersection grouping and coordination," IEEE Access, vol. 6, pp. 30128-30136, 2018.

[67] S. C. Ho, W. Y. Szeto, Y.-H. Kuo, J. M. Y. Leung, M. Petering, and T. W. H. Tou, "A survey of dial-a-ride problems: literature review and recent developments," Transportation Research Part B: Methodological, vol. 111, pp. 395-421, 2018.

[68] M. M. Solomon, "Algorithms for the vehicle routing and scheduling problems with time window constraints," Operations Research, vol. 35, no. 2, pp. 254-265, 1987.

[69] S. W. Wang, L. S. Sun, and J. Rong, "Catchment area analysis of Beijing transit Stations," Journal of Transportation Systems Engineering and Information Technology, vol. 13, no. 3, pp. 183-188, 2013. 